\title{
Has Dongying developed to a ghost city? - Evidence from multi-temporal population estimation based on VHR remote sensing and census counts
}

\section{Tobias Leichtle ${ }^{1,2}$, Tobia Lakes ${ }^{2}$, Xiao Xiang $\mathrm{Zhu}^{3,4}$, and Hannes Taubenböck ${ }^{1}$}

1 German Aerospace Center (DLR), German Remote Sensing Data Center (DFD), Münchner Straße 20, 82234 Weßling, Germany, tobias.leichtle@dlr.de

2 Humboldt-Universität zu Berlin, Geography Department, Rudower Chaussee 16, 12489 Berlin, Germany

3 German Aerospace Center (DLR), Remote Sensing Technology Institute (IMF), Münchner Straße 20, 82234 Weßling, Germany

4 Technical University of Munich (TUM), Signal Processing in Earth Observation (SiPEO), Arcisstraße 21, 80333 Munich, Germany

\section{ABSTRACT}

With ongoing growth and continuous development of cities, the world is turning into an urban society. In this context, urbanization, population growth and migration towards urban areas are global trends. These processes are highly dynamic especially in China, with highest rates of urbanization worldwide. In contrast to these wellknown trends, a recently emerging and rarely studied side effect is "ghost cities", which became a notable phenomenon in China recently. A ghost city is commonly defined as a new urban development that is running at severe undercapacity with respect to population and businesses and where the availability of housing and public infrastructure significantly exceeds the practical demand. Against this background, this study presents a framework based on remote sensing for the assessment of the presence or absence of the ghost city phenomenon in a typical highly dynamic Chinese city. For this purpose, remote sensing data with very-high resolution (VHR) are employed for establishment of a $4 \mathrm{~d}$ functional city model and subsequent population capacity estimation based on a statistical approach. Regarding the components of the functional $4 \mathrm{~d}$ city model, the multi-temporal building model and classification of building types associated with residential and non-residential function 
returned very high accuracies with $\kappa$ of 0.73 and 0.89 , respectively, while the number of floors was estimated with coefficient of determination of 0.91 . Compared to the numbers of official census counts, the multi-temporal population capacity estimation revealed a considerable mismatch of available living space based on VHR remote sensing data and actual population counts. According to the conceptual framework of this study, this disagreement indicates a high likelihood and significant evidence for the emergence and presence of the ghost city phenomenon for the city of Dongying. In addition, a detailed spatial assessment was conducted in terms of an index comparing the dynamics of residential developments and population numbers to provide an impression of specific regions of the urban area which are most likely to suffer from the ghost city phenomenon.

\section{KEYWORDS}

Urbanization, VHR remote sensing, 4d functional city model, population estimation, ghost city, China

\section{INTRODUCTION}

Urbanization, population growth and displacement of population concentration towards cities are global trends. These processes keep turning the world into an urban society as the largest parts of the additional population is projected to become urban dwellers (United Nations, 2014). This trend is especially dynamic in China, with highest urbanization rates worldwide (Seto, et al., 2011; Taubenböck, et al., 2014). The urban share of the total population increased by almost 30 percent within the past three decades, and growth rates are projected to persist in the future (World Bank \& Development Research Center of the State Council, 2014). With respect to the physical expansion of urban areas, the spatial extent of urban land in China has tripled during the past 30 years while the expansion reached a factor of five in the dynamic coastal provinces in the South-East of China (Schneider \& Mertes, 2014).

In this regard, remote sensing has proven an adequate tool for quantitative measurement and continuous observation of the urban built-up extent and its spatial expansion at global (Schneider, et al., 2010; Taubenböck, et al., 2012) as well as at national scale, e.g., with respect to China (Li \& Gong, 2016; Shi, et al., 2017; Xie \& 
Weng, 2016). In literature, numerous methods for mapping and monitoring of urban built-up extent exist using various types of remote sensing data at different spatial scales. For example, Schneider, et al. (2010) utilize 500m MODIS data for global classification of urban land cover, while the authors of Taubenböck, et al. (2012) employ multi-temporal Landsat and TerraSAR-X imagery for monitoring of megacities worldwide at a spatial resolution of $30 \mathrm{~m}$. Another data source is multi-temporal nighttime light imagery, which is used for global mapping of urbanization dynamics (Ma, et al., 2015; Zhang \& Seto, 2011). Although very-high resolution (VHR) remote sensing imagery (i.e. data with spatial resolution of $1 \mathrm{~m}$ or less) became more and more available and accessible, no studies at global or very large scales (such as the national scale of China) exist to date. However, several recent studies have demonstrated the feasibility of monitoring the physical expansion and structural urban transformation for smaller test sites (e.g., Huang, et al. (2017), Lefebvre and Corpetti (2017), Leichtle, et al. (2017a)).

A well and widely known phenomenon with respect to urbanization in China is rural-urban migration, which has persisted for the last decades and was studied intensively in literature (e.g., Liang (2001), Zhang and Song (2003), Chan (2012)). In accordance with the spatial expansion of cities, rural-urban migration was and remains strongly directed towards the coastal provinces in the South-East of China (Chan, 2012). Chan (2012) estimated a number of 200-250 million rural residents that have moved to Chinese cities within the past three decades. Despite this continuous and massive process of rural-urban migration in China, a completely different, emerging and less studied phenomenon are so-called ghost cities. Briefly, a ghost city can be described as a „,new development that is running at severe undercapacity, a place with drastically fewer people and businesses than there is available space for" (Shepard, 2015). According to Shepard (2015), ghost cities have become a notable phenomenon in China in recent times.

Against this background, this study aims to provide a framework for assessing the ghost city phenomenon by means of multi-temporal VHR remote sensing data. The objective of this study is the assessment of the presence or absence of the ghost city phenomenon based on the multi-temporal confrontation of available living space of residential buildings (i.e. population capacity) delineated from VHR remote sensing data and multi-temporal population counts from census. For this purpose, a $4 \mathrm{~d}$ functional city model is established (Section 4.2), comprising a multi-temporal building model, classification of building types associated with residential and nonresidential function (i.e. with regard to permanent residential population) as well as building height in terms of the number of floors. Based on these multi-temporal physical morphologic characteristics of the built environment, a statistical approach is applied for multi-temporal population capacity estimation (Section 4.3). 
The relationship between the multi-temporal evolution of a city's morphologic configuration, building function and related population capacity estimates and the temporal development of its respective census counts enables the assessment whether the ghost city phenomenon is existent or not (Section 4.4). In this study, the city of Dongying serves as an example of a typical highly dynamic medium sized Chinese city, which may suffer from the ghost city phenomenon.

\section{GHOST CITIES OF CHINA}

The term ghost city (or alternatively ghost town, ghost estate) was originally used for empty or unfinished residential developments in Ireland which occurred as a consequence of the global financial crisis (O'Callaghan, et al., 2014). However, the phenomenon of ghost cities became also notable in China recently (Shepard, 2015). As opposed to ghost estates in other countries around the globe which mostly arise from abandoned old residential developments (O'Callaghan, et al., 2014; Thompson \& de Beurs, 2018; Xie, et al., 2018), a Chinese ghost city is unique since completed new buildings are affected (He, et al., 2016). As mentioned above, a ghost city in China is defined as a new urban development running at severe undercapacity, a place which houses drastically fewer people and businesses than there is space available (Shepard, 2015). A very similar definition is given by Zheng, et al. (2017b), who characterize ghost cities by three main features: low population density, low luminosity intensity, and extensive non-lit built-up areas. In another study, Zheng, et al. (2017a) define ghost cities likewise as areas of low intensity of anthropogenic activities and dark built-up areas with few lights at night. Jin, et al. (2017) associate ghost cities with low urban vitality of new residential developments, which is defined according to urban morphology, functional aspects, and social indicators. Finally, the authors of Ma, et al. (2018) relate ghost cities to imbalanced urbanization of land and population as well as low nighttime light intensity.

2.1 Background of the ghost city phenomenon in China

In China, several political, demographic and related spatial policies influence urbanization and population development, which have effects on the evolution of the ghost city phenomenon. Chinese urbanization and 
migration of rural population towards cities has increased massively since the 1980s and remains high at an unprecedented rate (Ren, 2013). However, in contrast to many cities of the Global South, urban development and planning as well as migration of population is controlled by administrative orders and master plans from the Chinese government (Ruibo \& Linna, 2013). Thus, urban planning in China has become a strategic governmental instrument to relieve the pressure on rapidly growing cities (Shepard, 2015) or to promote economic growth of selected cities and provinces (Ren, 2013). In addition, the sale of land use rights for urban development has become an important source of revenue and taxes for the local governments, who are consistently reinforcing this approach (Zheng, et al., 2014). However, the population development in China is strongly controlled by the hukou (household registration) system, which assigns a registration status of urban or rural to each citizen that can only be changed by the government (Ren, 2013). Thus, permanent migration from rural to urban areas in the formal sense (i.e., hukou migration) is highly regulated and mostly only possible for the very rich, the highly educated or direct family members of citizens with urban hukou (Chan \& Buckingham, 2008). Therefore, the number of hukou migrants has been remaining relatively stable at low numbers since the 1990s (Chan, 2012). For these reasons, construction of new residential areas has increased much faster than the urban population in some areas, which implies an increasing number of vacant apartments (Zheng, et al., 2014). In turn, such situations depict the starting point for the emergence of the ghost city phenomenon.

\subsection{Current state of ghost cities in China}

One of the most famous ghost cities in China known from the public media is Ordos Kangbashi in Inner Mongolia, which was established in 2003 after the discovery and development of coal and gas deposits in the beginning of the 21 st century (Shepard, 2015). Besides this popular example, several other ghost cities are collected by means of rankings and listings from different sources. Since 2014, the Chinese third-party organization Standard Ranking has been publishing an annual list of the top 50 ghost cities identified by means of low population density within the built-up area, setting the threshold to 5500 people / $\mathrm{km}^{2}$ (Standard Ranking, 2015). In 2015, the real estate portal of Fang Holdings (www.fang.com) published a list of 12 ghost cities in China based on the decline of prices in the local residential real estate market (Fang Ranking, 2015). Another list was published in 2015 by the Chinese internet technology company NetEase (www.163.com), who indicate ghost cities by declining population growth and density accompanied by an increasing growth rate of the urban land area and conclude a concentration of ghost cities in the Northeast of China as well as in coastal areas of 
Shandong province (NetEase Ranking, 2015). Besides their own analyses, the authors of Jin, et al. (2017) conducted a keyword search (name of each city + "ghost city" in Chinese) on the Chinese search engine Baidu (www.baidu.com) and created a list of ghost cities in order to assess the public sense for this phenomenon. A complete reprint of these lists and rankings can be found in the appendix section of Jin, et al. (2017).

The most common to all of these lists and rankings is that they have only few cities in common. In fact, not a single city was identified as a ghost city by all four assessments. Although the list published by NetEase found some spatial concentration patterns of ghost cities, no general nationwide distribution of ghost cities in China could be identified. Thus, more objective and scientific profound methodological frameworks for the assessment of the ghost city phenomenon are required.

2.3 Scientific assessment of the ghost city phenomenon

In the context of scientific analysis of the ghost city phenomenon, only few and very recent studies exist. The most comprehensive overview of ghost cities in China is given by Shepard (2015), who precisely describes their background, causes, implications, and potential future development from a theoretical perspective. A practical study on ghost cities is presented by Chi, et al. (2015), who identify vacant housing areas indicating ghost cities based on cellphone positioning data at national scale in China. Jin, et al. (2017) developed a ghost city index for all Chinese cities by multi-temporal evaluation of the vitality of cities based on the number of road junctions, functionality at block level, and location based services (LBS) data. Another study in this context is presented by Zheng, et al. (2017b), which is one of only two known studies to date utilizing remote sensing data for the detection of ghost cities at medium to high spatial resolution. In their study, Zheng, et al. (2017b) employ remote sensing data from multiple sources (i.e., nighttime lights, land cover, and gridded population data) and propose an index for ghost city identification in the Yangtze River Delta. The second study based on remote sensing data from a similar group of authors (Zheng, et al., 2017a) proposes a slightly different ghost city index based on built-up area compared to nighttime light imagery and demonstrates this approach in Northeast China for the detection of ghost cities. In a similar manner, Ma, et al. (2018) introduce an improved ghost city index which relates the match-degree of the development of built-up area and population development to nighttime light imagery in the city of Ordos. 
These studies show capabilities and limitations of remote sensing data for assessing the ghost city phenomenon; however, none of these approaches employs VHR imagery for detailed assessment at the building level. Furthermore, a detailed discrimination of residential and non-residential function related to building types as well as the vertical dimension of urban areas is neglected throughout. In addition, most of the related work does not consider the multi-temporal aspect of the ghost city phenomenon.

\section{CONCEPTUAL FRAMEWORK}

Summarizing the definitions as well as the findings of existing studies on the ghost city phenomenon in China (Section 2), the most common feature of ghost cities is severe undercapacity with respect to population and businesses within the built-up area while the reliable identification remains challenging. Against this background, the conceptual framework for assessment of the ghost city phenomenon in this study is based on the multi-temporal confrontation of available living space of residential buildings (i.e. population capacity) measured by means of VHR remote sensing and multi-temporal population counts (i.e. permanent residential population) from official census data. Compared to exiting studies, especially the multi-temporal assessment adds robustness to the analyses since uncertainties can be reduced by consideration of temporal trends. Thus, the conceptual definition of the ghost city phenomenon in this study is based on the hypothesis that the available living space massively exceeds the actual population within the study area.

Based on this hypothesis, the deductive methodological framework of this paper is presented in Fig. 1. For estimation of the multi-temporal residential population capacity, a $4 \mathrm{~d}$ functional city model is established based on a multitude of input data. This model encompasses three components with respect to the characteristics of the physical built environment: First, a multi-temporal building model is developed by means of object-based change detection of individual buildings using VHR remote sensing data. Second, building types associated with residential and non-residential function are classified for both time steps. Third, building heights from a remote sensing based digital surface model are transformed to number of floors for each building. The multi-temporal population capacity is estimated statistically based on the available living space and opposed to multi-temporal population counts which are collected from official census data. Based on the comparison of the estimated population capacity and actual population counts, the presence or absence of the ghost city phenomenon can be assessed. Especially the dynamics of these numbers increase the validity of this study since the multi-temporal 
assessment mitigates uncertainties due to consideration of only one snapshot in time. Thus, if the temporal evolution of the estimated population capacity massively exceeds the change of actual population counts, the presence of the ghost city phenomenon is highly likely according to the definition and hypothesis in this paper.

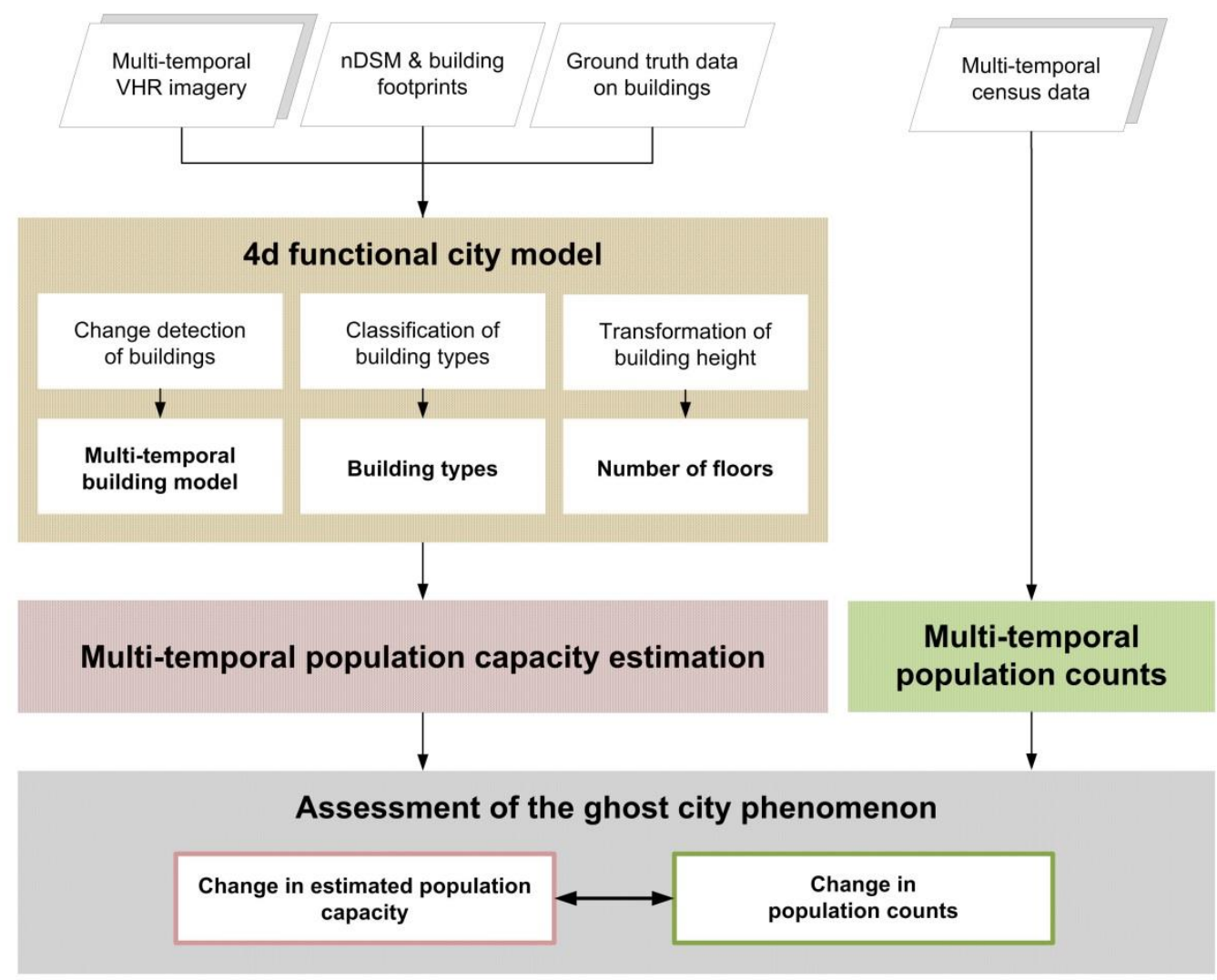

Fig. 1: The methodological framework of this study.

For demonstration and application of the proposed methodology, a rapidly growing urban area in Shandong province is selected as study area (Fig. 2). The analysis focuses on the largest and most important city within the area of the Yellow River Delta (YRD), Dongying (Fig. 2a). After the discovery and development of Shengli Oil Field in the 1960s, the city of Dongying was established in 1983 to harbor oil related industries and its workers (Kuenzer, et al., 2014). Since then, the YRD has undergone a rapid economic development accompanied by heavy urbanization and population growth (Ottinger, et al., 2013). In Dongying, the local government aims to develop the city as a "national highly-efficient ecological industry base" (Comitee of the Dongying urban and rural planning bureau, 2011) and is expediting construction and urbanization. Within its only 30 years of history, the city of Dongying raised to highest recent urbanization rates of the six biggest cities in Shandong province 
(Xu, et al., 2009). In case of Dongying, some studies report the presence of the ghost city phenomenon (e.g., Chi, et al. (2015)), whereas other studies do not characterize it as a ghost city (e.g., Standard Ranking (2015)). Although Dongying is not included in the top 30 ghost cities of China in Jin, et al. (2017), it exhibits a relatively high ghost city index according to the authors definition and analyses. Thus, the practical aim of this study is to clarify the presence or absence of the ghost city phenomenon for the city of Dongying as a typical example of a rapidly growing medium sized Chinese city which may suffer from the ghost city phenomenon.

a) Overview of Dongying municipalities
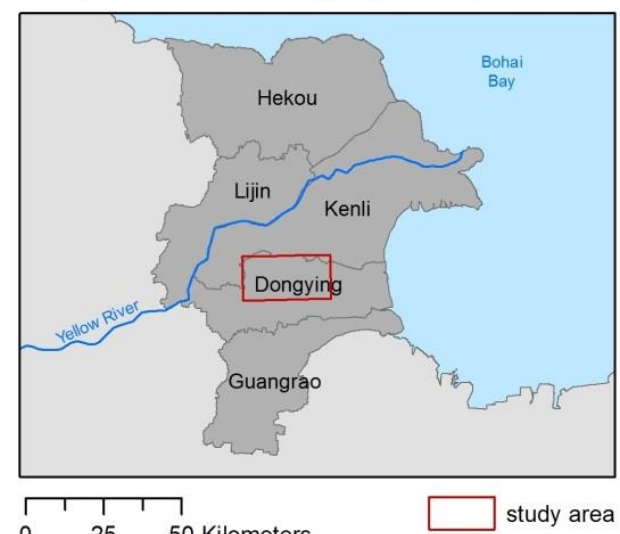

$0 \quad 25 \quad 50$ Kilometers

c) QuickBird imagery $2006 / 2007$

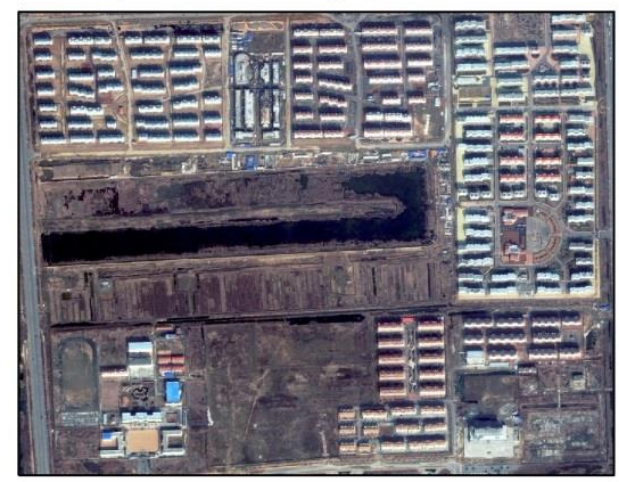

\begin{tabular}{l|c|c|c|c|c|}
\hline & 1 & 1 & & \\
0 & 250 & 500 Meters
\end{tabular} b) Pléiades nDSM \& building footprints 2013

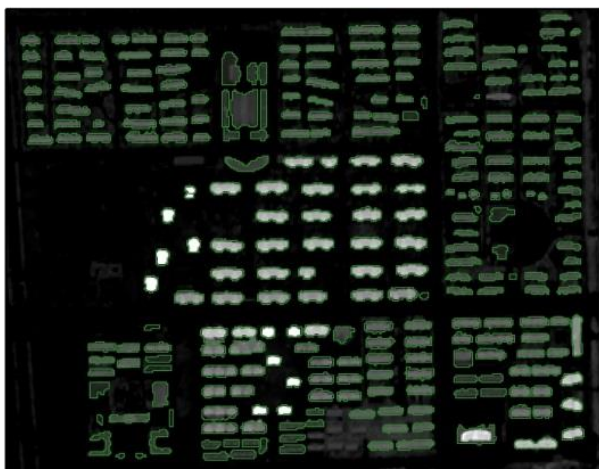

nDSM height [m]

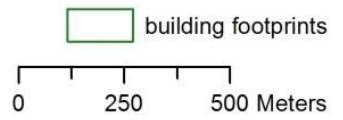

50

d) WorldView imagery 2013

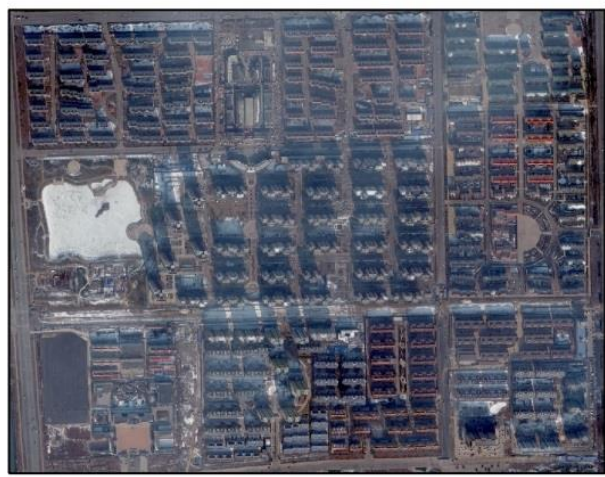

\begin{tabular}{l|c|c}
\hline & 1 & 1 \\
0 & 250 & 500
\end{tabular} Meters
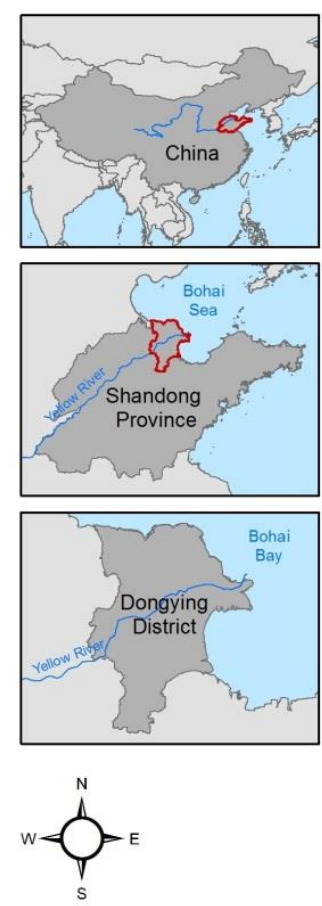

Fig. 2: Location of the study area and available data sets: a) Overview of the five municipalities in Dongying district and extent of the study area corresponding to the city of Dongying (red frame), b) Zoomed area from the Pléiades normalized digital surface model (nDSM) and derived building footprint geometries, c) Details of the QuickBird imagery from 2006/2007 ( $\left.\mathrm{t}_{0}\right)$, and d) Details from WorldView imagery acquired in $2013\left(\mathrm{t}_{1}\right)$. 


\section{DATA \& METHODS}

4.1 Data Sets

4.1.1 Remote sensing data

\section{Multi-temporal VHR remote sensing imagery}

The VHR remote sensing imagery serves as the basis for the multi-temporal analysis and consists of two multispectral images with very high spatial resolution. The first image is a mosaic of two QuickBird images which were acquired on March 30, 2006 and February 25, 2007 with off-nadir view angles of 5.7 and $14.2^{\circ}$, respectively (a zoomed area is shown in Fig. 2c). Based on their close temporal relationship, these images are treated as the first time step 2006/2007 (i.e. $\mathrm{t}_{0}$ ). The second image mosaic from 2013 (considered as $\mathrm{t}_{1}$ ) consists of three WorldView-2 acquisitions with one image recorded on January 1, 2013 and two images from January 17, 2013 (a zoomed area is shown in Fig. 2d). The three acquisitions possess off-nadir view angles of $18.1^{\circ}$, $22.5^{\circ}$, and $15.9^{\circ}$, respectively. Both image mosaics exhibit four spectral bands (blue, green, red, and near infrared (NIR)) and were rescaled to a spatial resolution of $50 \mathrm{~cm}$ using nearest neighbor resampling. The multitemporal image mosaics were properly co-registered with mean RMSE (root mean square error) of 1.5 pixels (i.e. $0.75 \mathrm{~m}$ ) and atmospherically corrected using the ATCOR (Atmospheric and Topographic Correction) toolbox (Richter, 1996).

\section{Normalized digital surface model (nDSM) and building footprint geometries}

Building footprint geometries corresponding to the year $2013\left(\mathrm{t}_{1}\right)$ are available for the urban part of Dongying municipality, i.e. the spatial extent of the city of Dongying (red box in Fig. 2a). The building footprints were extracted semi-automatically from a normalized digital surface model (nDSM) acquired on October 18, 2013 with spatial resolution of $4 \mathrm{~m}$ utilizing the segmentation and classification procedure presented in Wurm, et al. (2011). The nDSM also provides building height, whereas the median value of all pixels within each building footprint is utilized (also see Tab. 2). Building heights based on the nDSM possess a coefficient of determination $\left(r^{2}\right)$ of 0.98 compared to building heights from in situ measurements. In addition, the extracted buildings have been checked and corrected manually in order to ensure high reliability (a zoomed area shown in Fig. 2b). The 
availability of building footprints delimitates the study area of this paper, which encompasses a total of 30,695 buildings.

\subsubsection{Ground truth data on buildings}

Ground truth information and reference data on building objects is available for calibration and validation purposes of the $4 \mathrm{~d}$ functional city model. Changed buildings are defined as newly constructed buildings in this study and reference data on building change was collected via visual inspection of the multi-temporal VHR remote sensing imagery. Accordingly, 7,433 building labels are available for accuracy assessment of change detection which are divided into 3,430 changed and 4,003 unchanged building objects, respectively. Ground truth information on building types associated with residential and non-residential function, which is defined with regard to the occupancy of permanent residential population, as well as height information according to the number of floors is available from field data acquired in October 2013. During this field campaign, the building type and its associated function were determined and the number of floors was counted visually. Within the scope of this study, building functions are reduced to two classes: residential and non-residential, whereas the latter class comprises several classes of building functions (e.g., industrial, commercial, or office buildings). In total, 709 samples on building functions are available, which are separated into 468 residential and 241 nonresidential buildings.

\subsubsection{Multi-temporal census data}

Census data are available from the statistical yearbooks of Shandong province for the past 15 years, i.e., from 2000 until 2015 (Shangdong Provincial Bureau of Statistics, 2001-2016), which covers the years that are relevant with respect to the remote sensing data sets (i.e. 2006/2007 ( $\left.\mathrm{t}_{0}\right)$ and $\left.2013\left(\mathrm{t}_{1}\right)\right)$ and gives an additional impression of the more long-term trends. This data on the actual permanent residential population is available for all five municipalities in Dongying district. Although the study area largely covers Dongying municipality (Fig. 2a), the incorporation of the evolution of census counts within the spatial extent of the district area allows for consideration of population development in the wider context of the YRD. 
$4.24 \mathrm{~d}$ functional city model

\subsubsection{Change detection of buildings}

In this study, multi-temporal VHR remote sensing data are utilized together with building footprint geometries for object-based change detection in order to derive the multi-temporal building model. The object-based change detection approach is based on the unsupervised methodology presented in Leichtle, et al. (2017a).

For the purpose of change detection, building geometries are used to derive object-based features based on the multi-temporal VHR images. Features from different categories, i.e. first-order statistics of the multispectral bands, ratio features, and second-order statistics based on the grayscale image are utilized (Tab. 1). The objectbased features are calculated individually from each VHR image and subsequently combined by means of object-based feature differencing (i.e., difference feature vector) in order to incorporate the temporal relationship implicitly. To ensure equal weighting within the difference feature vector, minimum-maximum normalization is employed to introduce a common range of values of $[-1,1]$.

Tab. 1: Object-based features for change detection.

\begin{tabular}{lll}
\hline Multispectral features (10) & Ratio features (11) & Grayscale texture features (12) \\
\hline mean intensity of blue band & blue / green & GLCM angular 2nd moment \\
mean intensity of green band & blue / red & GLCM contrast \\
mean intensity of red band & blue / NIR & GLCM correlation \\
mean intensity of NIR band & green / red & GLCM dissimilarity \\
mean intensity of all bands (brightness) & green / NIR & GLCM entropy \\
standard deviation of blue band & red / NIR & GLCM homogeneity \\
standard deviation of green band & normalized green & GLCM mean \\
standard deviation of red band & normalized red & GLCM standard deviation \\
standard deviation of NIR band & normalized NIR & GLDV angular 2nd moment
\end{tabular}




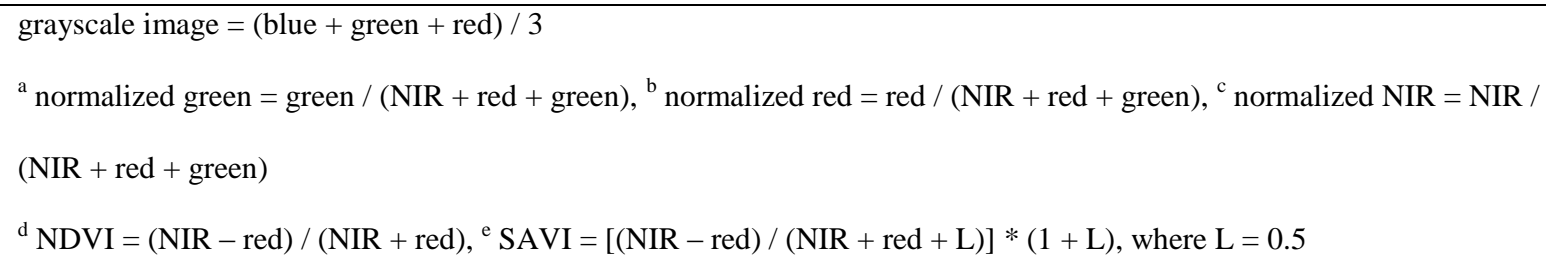

As a final step of feature preprocessing, principal component analysis (PCA) is employed in order to eliminate inevitable correlations and thus redundant information from the object-based difference features in Tab. 1. For this purpose, a tripartite procedure is deployed in order to determine the number of relevant principal components (PCs). In this manner, the Bartlett's test is used as a precondition, while the number of relevant PCs is determined by a combined threshold condition of cumulative proportion of explained variance and an averaged parallel analysis (Leichtle, et al. (2017a)).

Subsequently, clustering is utilized for discrimination of changed and unchanged buildings based on the relevant PCs of all features. In this paper, four different clustering algorithms that have proven their utility for unsupervised change detection according to Leichtle, et al. (2017b) are applied for change detection: k-means, partitioning around medoids (PAM), genetic k-means, and the self-organizing map (SOM) clustering approach. Finally, the two partitions of the building inventory are labeled according to changed and unchanged buildings.

The subsequent classification of building types, transformation of height to the number of floors, as well as estimation of population capacity assume that these respective characteristics are stable and do not change within the observation period of 6/7 years. Thus, the information on changed and unchanged buildings is directly incorporated at building level as a precondition for all other components of the $4 \mathrm{~d}$ functional city model and changed buildings are excluded from the first time step (i.e. $\mathrm{t}_{0}$ ).

\subsubsection{Classification of building types}

Building types are classified based on building geometries and ground truth information on residential and non-residential function. According to Wurm, et al. (2016), shape-based features related to building footprints 
possess high discriminative power for building types classification. The utility of the shape of buildings is also demonstrated in Geiß, et al. (2015) and Xie, et al. (2015), where the spatial context of buildings within building blocks is included in terms of additional features. The spatial relationship of buildings is also employed by Lu, et al. (2014) for classification of building types. The current study combines features from these studies, whereas the spatial relationship of buildings is incorporated at the block level, which is defined according to the road network (Tab. 2).

Tab. 2: Object-based features for building types classification based on Wurm, et al. (2016), Geiß, et al. (2015), Xie, et al. (2015), and Lu, et al. (2014).

\begin{tabular}{|c|c|c|c|c|}
\hline $2 \mathrm{~d}$ statistics & $2 \mathrm{~d}$ shape features & 3d statistics & $3 \mathrm{~d}$ shape features & $\begin{array}{l}\text { Spatial relationship of } \\
\text { buildings within block }\end{array}$ \\
\hline area & compactness & median height & volume / area & mean distance \\
\hline perimeter & roundness & volume & $\begin{array}{l}\text { volume / } \\
\text { perimeter }\end{array}$ & $\begin{array}{l}\text { distance to nearest } \\
\text { building }\end{array}$ \\
\hline area / perimeter & shape index $2 d$ & & shape index $3 d$ & mean area \\
\hline length & asymmetry $2 \mathrm{~d}$ & & asymmetry $3 \mathrm{~d}$ & SD of area \\
\hline width & density & & & mean volume \\
\hline \multirow[t]{8}{*}{ length / width } & rectangular fit & & & SD of volume \\
\hline & elliptic fit & & & mean density \\
\hline & border index & & & SD of density \\
\hline & main direction & & & mean asymmetry \\
\hline & normalized perimeter index & & & SD of asymmetry \\
\hline & $\begin{array}{l}\text { normalized proximity index } \\
(\mathrm{nPI})\end{array}$ & & & mean main direction \\
\hline & normalized spin index (nSI) & & & $\mathrm{SD}$ of main direction \\
\hline & & & & built-up density \\
\hline
\end{tabular}

$\mathrm{SD}=$ standard deviation

The object-based features according to the shape of buildings and their spatial relationship within each block serve as input for supervised classification of building types using the Random Forest (RF) classifier (Breiman, 2001). The required input parameters for the RF classifier comprise the number of classification trees to be generated $\left(n_{\text {tree }}\right)$ and the number of features that are utilized at each node to establish a decision $\left(m_{\text {try }}\right)($ Belgiu 
\& Drăguţ, 2016). In the current study, the R software implementation presented by Liaw and Wiener (2002) is employed, where $n_{\text {tree }}$ is set to 500 and $m_{\text {try }}$ is defined as $\sqrt{p}$, with $p$ corresponding to the number of features. These values are initialized according to default values, which is also recommended by Belgiu and Drăguţ (2016)

Prior to training of the RF classifier, the features are scaled to a common range of values of $[0,1]$ in order to ensure equal weighting of all features. The ground truth information on building function is available for 709 sample buildings and separated into training and testing data picking a stratified random sample with partitioning of $85 \%$ training and $15 \%$ testing samples. Subsequently, the RF model is trained and applied to the complete set of buildings for classification of building types according to residential and non-residential function.

\subsubsection{Transformation of building height}

Since the statistical approach for population capacity estimation is based on the available living space per residential building in this study, building height must be transformed to number of floors for all buildings first (Fig. 3). For this purpose, the average floor height of buildings with residential function from the reference data set (Section 4.1.2) $h_{f l_{j}}\left(o_{b_{j}}=\right.$ residential) is calculated by linear transformation of building height from the nDSM. In this regard, the height of each reference building $\left(h_{b_{j}}\right)$ is divided by its number of floors $\left(n_{f l_{j}}\right)$, which is available through the nDSM and ground truth information (Section 4.1.2). The average floor height of the reference buildings is compared to the height of all buildings (i.e., their median nDSM value $\left(h_{b_{i}}\left(t_{b_{i}}=\right.\right.$ residential) $)$ ) to derive the number of floors $\left(n_{f l_{i}}\right)$ for all residential buildings within the study area. This step includes three threshold conditions based on building height and the statistics of the floor heights from the reference data (Fig. 3). The first condition excludes buildings with smaller height than the lowest building in the reference data $\left(n_{f l_{i}}=0\right)$. The second condition assigns one floor $\left(n_{f l_{i}}=1\right)$ to buildings that are lower than the average floor height but not included in the first condition. For buildings from the third condition (i.e., buildings with greater height than the average floor height from reference data), their height is divided by the average floor height for residential buildings to determine the number of floors $\left(n_{f l_{i}}\right)$. In this context, only full floors are considered, i.e. the number of floors $\left(n_{f l_{i}}\right)$ is generally rounded down. 
Reference buildings $b_{j}$

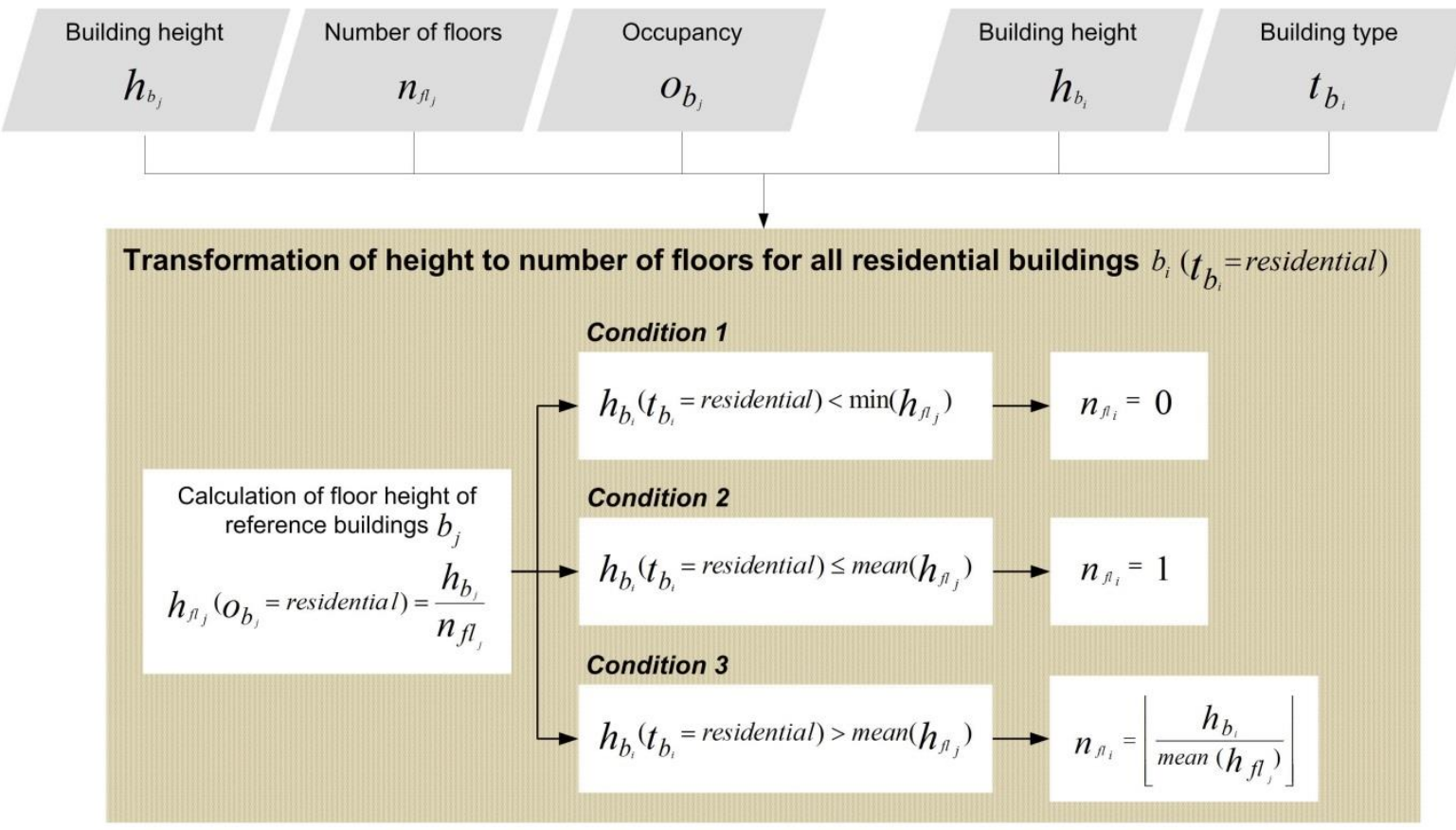

Fig. 3: Transformation of building height to number of floors for all buildings within the study area. Formulae index $\mathrm{j}$ refers to buildings from the reference data set, index $\mathrm{i}$ indicates the complete building inventory within the study area. For mathematical symbols and abbreviations see text.

\subsubsection{Validation of the $4 d$ functional city model}

For validation of the $4 \mathrm{~d}$ functional city model, each parameter (i.e., the multi-temporal building model, building types classification, and number of floors) is validated separately according to its respective ground truth information. For accuracy assessment of the multi-temporal building model as well as building types classification, the Kappa statistics (Foody, 2002), the F-score (Van Rijsbergen, 1979), as well as the True-SkillStatistics (TSS) (Allouche, et al., 2006) are calculated based on the respective ground truth information (Section 4.1.2). The linear transformation of building height to the number of floors is validated based on the reverse prediction of the number of floors using the average height per floor of reference buildings with residential function, whereas the coefficient of determination $\left(r^{2}\right)$ is calculated as a quantitative measure of accuracy. 


\subsection{Population capacity estimation}

Population capacity at the building level is estimated according to the statistical approach for population estimation (Biljecki, et al., 2016). The combination of the classification of building types and the area of building footprints together with the number of floors allows the spatial quantification of available living space. Fig. 4 presents the workflow for population capacity estimation. First, the available living space for each residential building $\left(l_{i}\left(t_{b_{i}}=\right.\right.$ residential $\left.)\right)$ is estimated by multiplication of the number of floors $\left(n_{f l_{i}}\right)$ with the area of each floor based on the building area $\left(a_{b_{i}}\right)$. Second, the population capacity of each building $\left(\right.$ pop $\left._{\text {capacity }_{i}}\right)$ is estimated based on the available living space $\left(l s_{i}\right)$ and statistical data on living space per capita $\left(l s_{\text {capita }}\right)$ available from the Comitee of the Dongying urban and rural planning bureau (2011). The estimated population capacity for each building is generally rounded down. Based on the multi-temporal building model, multitemporal population capacity estimates are established.

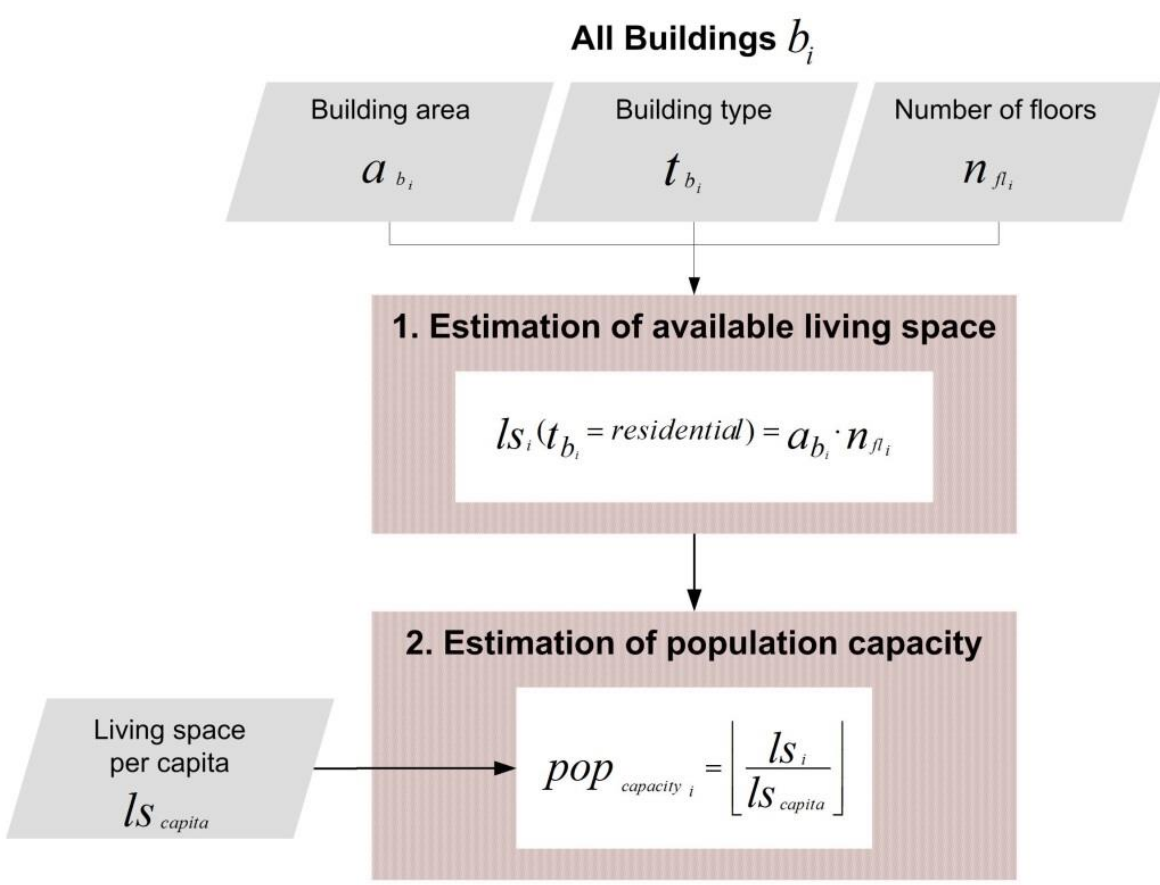

Fig. 4: Workflow for estimation of population capacity. For mathematical symbols and abbreviations see text. 
4.4 Assessment of the ghost city phenomenon

According to the conceptual framework of this study (Section 3), the presence or absence of the ghost city phenomenon is assessed by the comparison of multi-temporal population capacity estimates (Section 4.3) against multi-temporal census counts (Section 4.1.3). The estimated numbers of population capacity per building are summarized for the complete study area in order to approximate the administrative municipality level of census data. Accordingly, if the estimated population capacity massively exceeds population counts, the presence of the ghost city phenomenon is highly likely. In contrast, if these numbers correspond with each other or exhibit only slight variation, there is no indication for the presence of the ghost city phenomenon. In order to provide a more robust assessment, the dynamics of population capacity are opposed to the change of population counts in terms of multi-temporal assessment.

In addition, this comparison is also conducted in a spatially more detailed manner to provide an impression of specific regions within the urban area which are most likely to suffer from the ghost city phenomenon. According to the conceptual framework, a higher probability for the presence of the ghost city phenomenon can be assumed in areas of most recent residential developments based on constant or decreasing population numbers according to the census data. For the detailed spatial localization, the dynamics of the estimated population capacity $(e p c)$ and census counts $(c c)$ are scaled to relative values of $[-1,1]$ due to the deviation of spatial scales and consequent deviation of absolute numbers of both parameters (i.e., epc at building level, $c c$ on administrative units):

$$
\begin{aligned}
\rho e p c & =\frac{\Delta e p c}{|\max (\Delta e p c)|} \\
\rho c c & =\frac{\Delta c c}{|\max (\Delta c c)|}
\end{aligned}
$$

with $\Delta e p c=e p c\left(t_{1}\right)-e p c\left(t_{0}\right)$

and $\Delta c c=c c\left(t_{1}\right)-c c\left(t_{0}\right)$.

The dynamics of estimated population capacity and census counts are combined in terms of an index as follows:

$$
\frac{\rho e p c-\rho c c}{2}
$$


This index indicates the relationship of population capacity and actual number of residents with respect to the smallest spatial scale of inputs (i.e. the building level in this study) and possesses a range of values of $[-1,1]$. Accordingly, values towards 1 represent high likelihood for the presence of the ghost city phenomenon, while values around 0 refer to a proper degree of occupancy and low probability for the presence of a ghost city. Increasing census counts with simultaneous decreasing availability of living space (i.e. population capacity) result in negative values and would indicate housing shortage, i.e., the reverse situation of the ghost city phenomenon.

\section{RESULTS}

$5.14 \mathrm{~d}$ functional city model

\subsubsection{Multi-temporal building model}

For development of the multi-temporal building model and observation of the physical growth of the city of Dongying, the approach for unsupervised change detection was performed using different clustering algorithms on the WorldView-2 and QuickBird images from 2013 and 2006/2007, respectively. The change detection results of the four clustering algorithms (i.e., k-means, PAM, genetic k-means, and the SOM clustering approach) were compared according to their classification accuracy and the respective best result was used (Fig. 5a).

In general, Dongying is a highly dynamic city, which is clearly reflected by the results of change detection analysis. Within the considered time span of $6 / 7$ years, 12,875 new buildings were constructed, which corresponds to an increase of the building inventory of 72\%. As shown in Fig. 5a, new buildings were built more or less equally distributed within the city area of Dongying. Notably, complete blocks were established in most cases, whereas construction of single buildings represents an exceptional case. 
a) Multi-temporal building model 2006/2007 - 2013

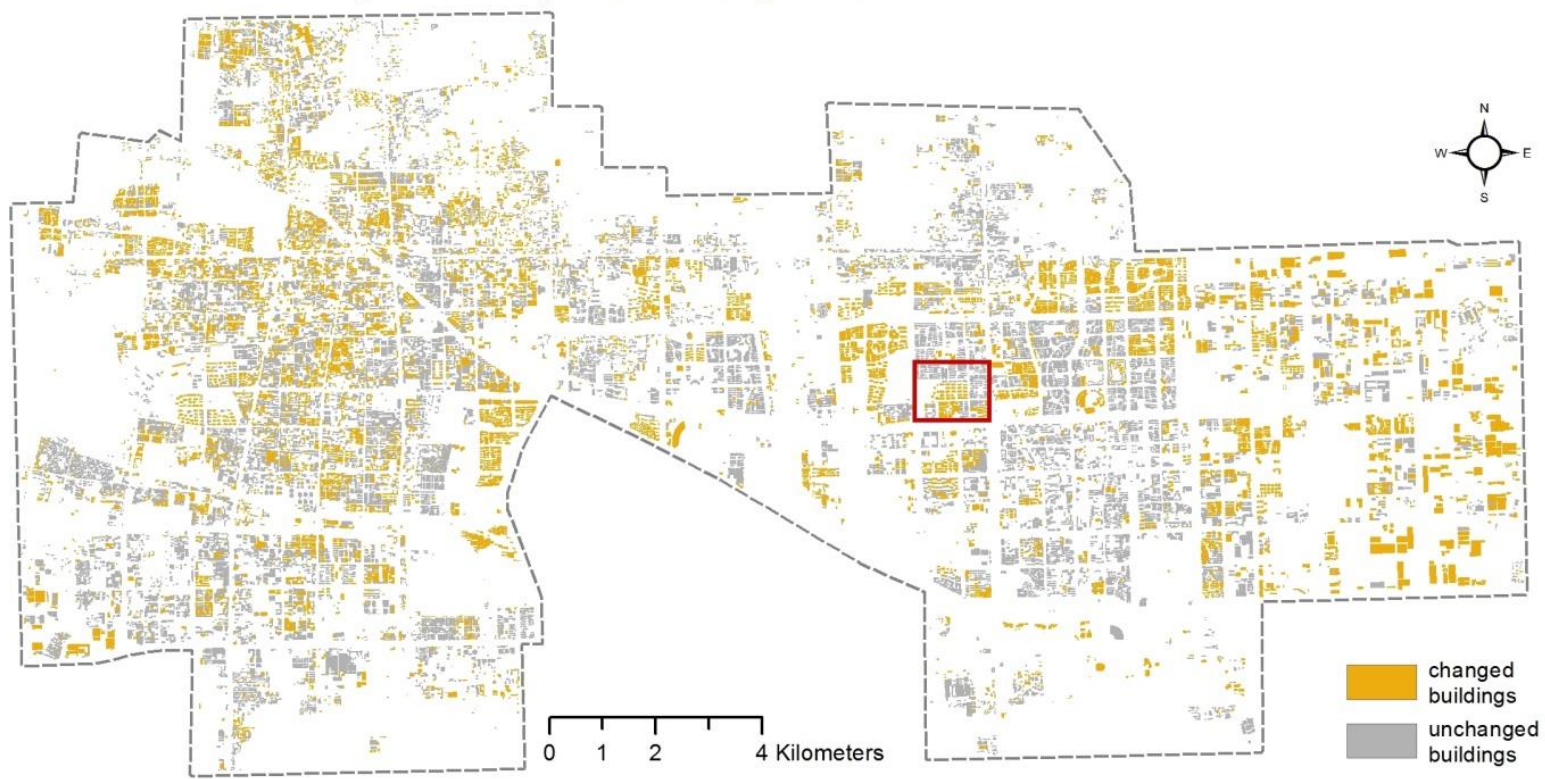

b) Building types classification

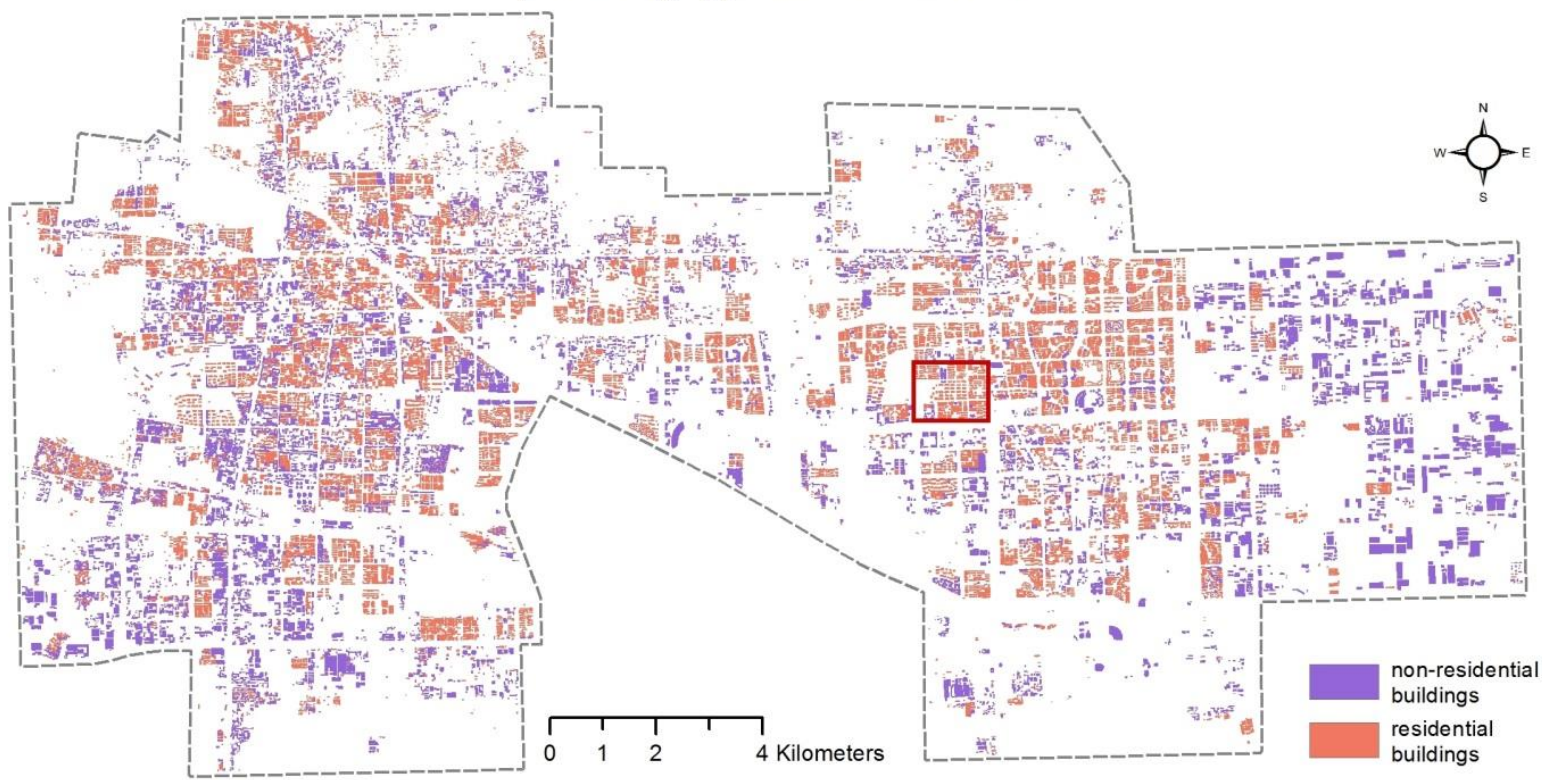

c) Details of multi-temporal building model and building types classification

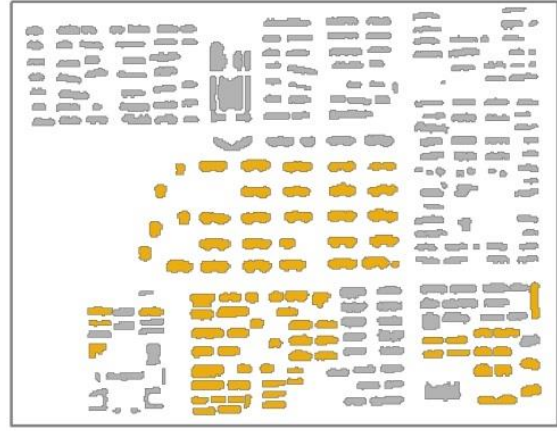

Multi-temporal building model

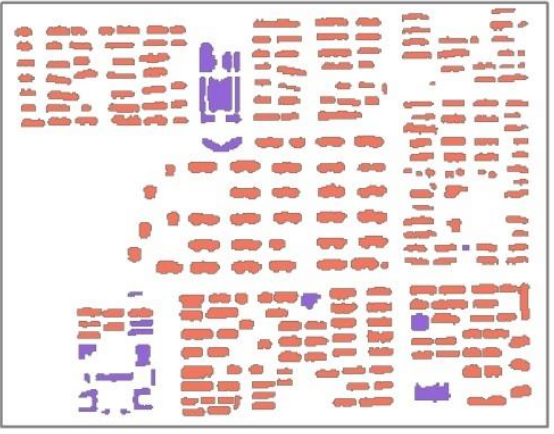

Building types classification

Fig. 5: Change detection and classification results in Dongying. a) Multi-temporal building model according to unsupervised change detection of QuickBird imagery from 2006/2007 ( $\mathrm{t}_{0}$ ) and WorldView-2 acquisitions from 
$2013\left(\mathrm{t}_{1}\right)$. b) Building types classification associated with residential and non-residential function. c) Details of the multi-temporal building model and building types classification.

\subsubsection{Building types}

The supervised RF classification of building types was conducted based on object-based features at building level (Tab. 2) and ground truth information according to residential and non-residential function (Section 4.1.2). After scaling of all features to a common range of values of $[0,1]$, the ground truth data were stratified and randomly sampled into $398+205$ training and $70+36$ testing samples for the two classes of interest (i.e., building types with respect to residential and non-residential function), respectively.

Fig. $5 b$ depicts the classification result of building types associated with residential and non-residential function. In total, 18,166 buildings were classified as residential and 11,821 were identified as non-residential. As shown in Fig. 5b, the majority of residential buildings are concentrated in the central parts of the city of Dongying, while non-residential buildings are located more towards the outskirts. Especially the Eastern part of the city is dominated by large non-residential buildings which can be allocated industrial function. Furthermore, building types are much more diverse in the Western part of Dongying, i.e. residential and non-residential buildings are allocated in a mixed manner at small spatial scales. In relation to the multi-temporal building model (Fig. 5a), 8,351 (65\%) newly constructed buildings correspond to residential function while 4,524 (35\%) account for non-residential buildings.

\subsubsection{Number of floors}

For the purpose of transformation of height from the nDSM to the number of floors for all residential buildings within the study area, the average height per floor was calculated using the relationship of building height and the number of floors for all reference buildings with residential function. Fig. 6 depicts the relationship between building height and the number of floors of the reference buildings which serves as the basis for linear transformation of building heights from the nDSM. In this study, an average height per floor of 
$2.88 \mathrm{~m}$ was empirically derived based on 468 buildings with residential function from the ground truth data set. Based on the average height per floor, the number of floors was calculated using the median height from the nDSM for all residential buildings within Dongying.

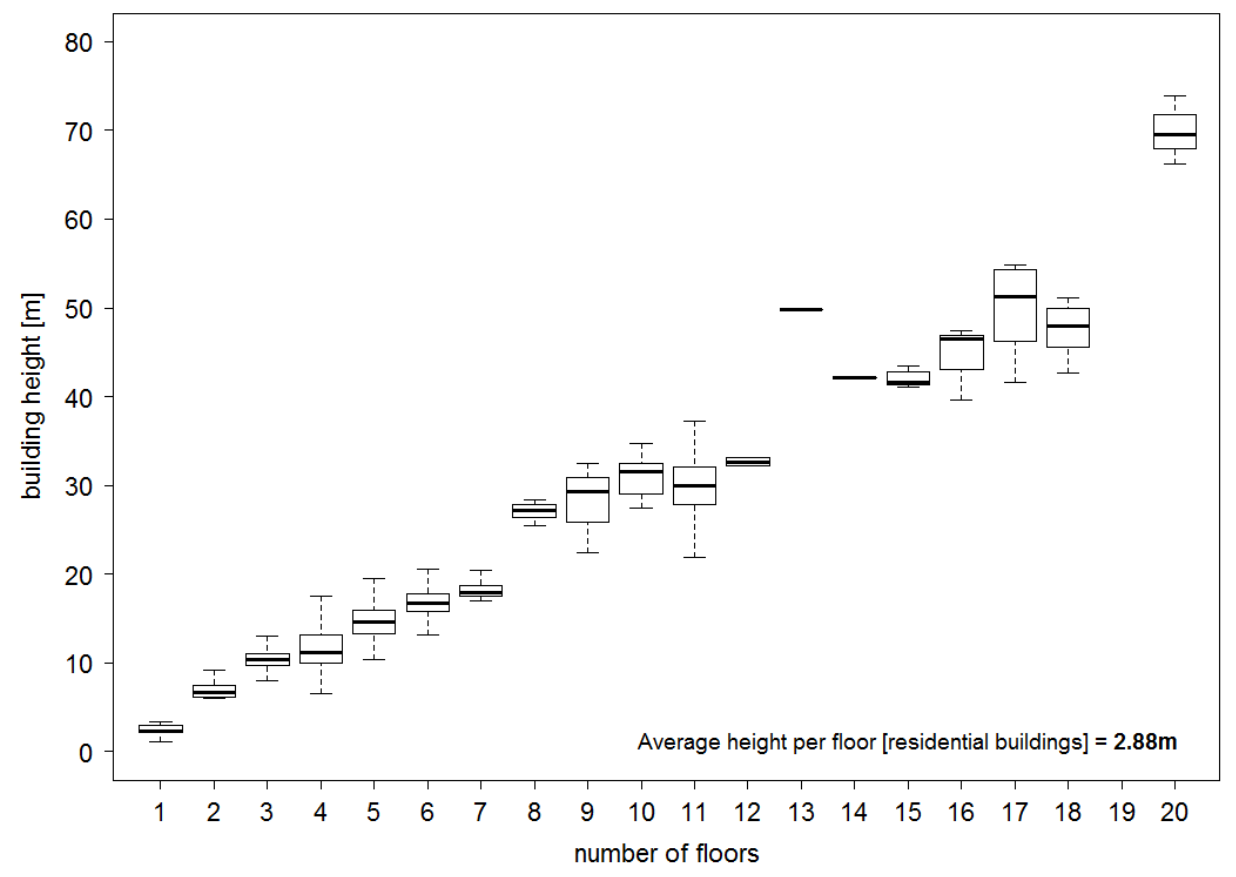

Fig. 6: Relationship of building height (i.e., median height from the nDSM per building footprint) and number of floors for 468 reference residential buildings within the study area.

\subsubsection{Validation of the $4 \mathrm{~d}$ functional city model}

For validation of the multi-temporal building model (Fig. 5a), the change detection accuracies of the four clustering algorithms were merged and returned final weighted accuracies of $\kappa=0.73, F=0.85$, and TSS $=$ 0.73 for the complete city extent. With respect to building types classification (Fig. 5b), the testing samples of the RF classification were used for validation with accuracies of $\kappa=0.89, F=0.93$, and TSS $=0.89$. The linear transformation of building height to the number of floors was validated according to the reverse prediction of the number of floors with a coefficient of determination of 0.91 . 
5.2 Population capacity estimation

The $4 \mathrm{~d}$ functional city model serves as input for multi-temporal population capacity estimation according to Fig. 4. The population capacity was calculated based on the available living space per building and the statistical living space per capita, which is 35 square meters per person for the city of Dongying according to the Comitee of the Dongying urban and rural planning bureau (2011). Fig. 7a shows the estimated population capacity for all residential buildings in Dongying for the year 2013. The population capacity for 2006/2007 (Fig. 7b) is given implicitly based on the multi-temporal building model. 
a) Estimated population capacity 2013

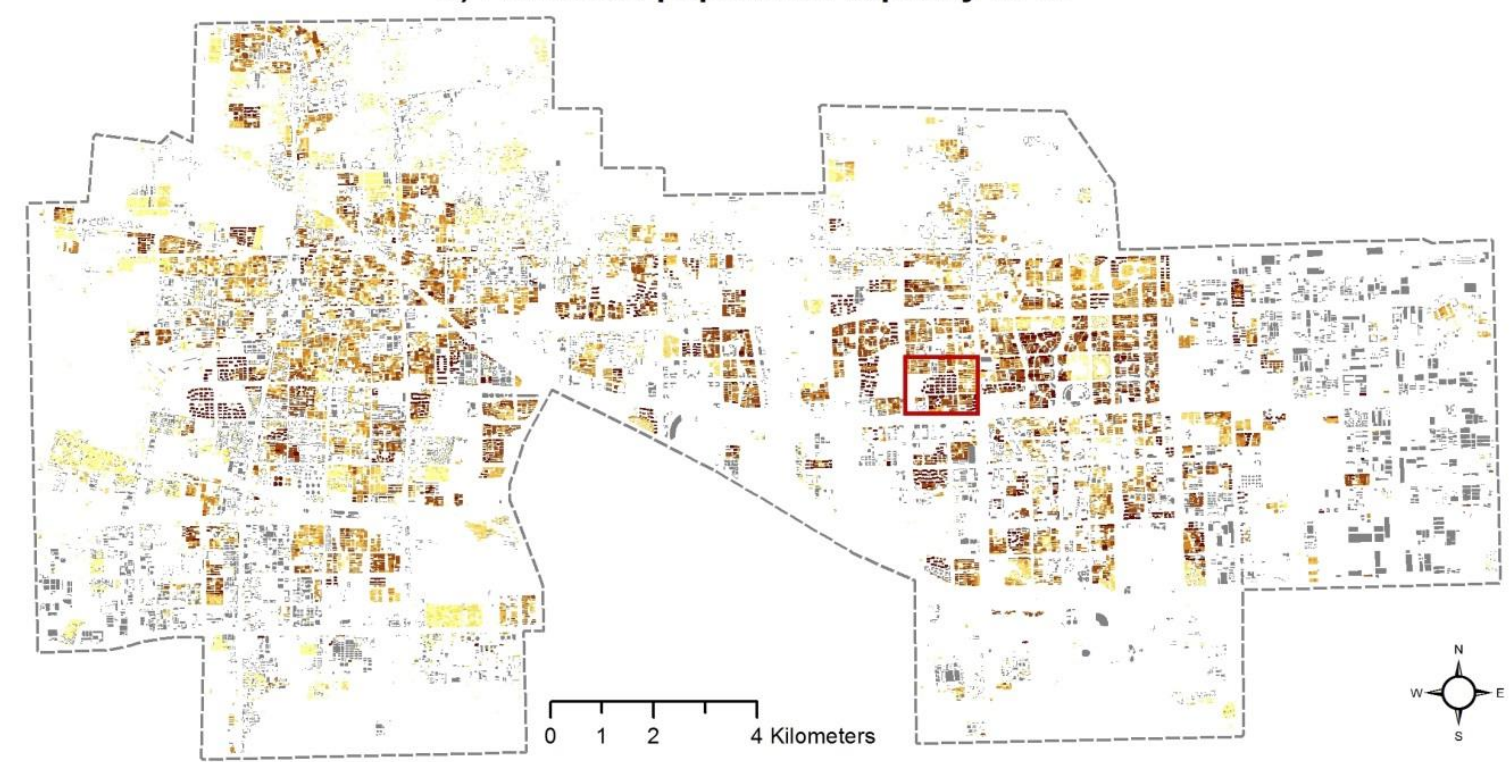

b) Estimated population capacity $2006 / 2007$

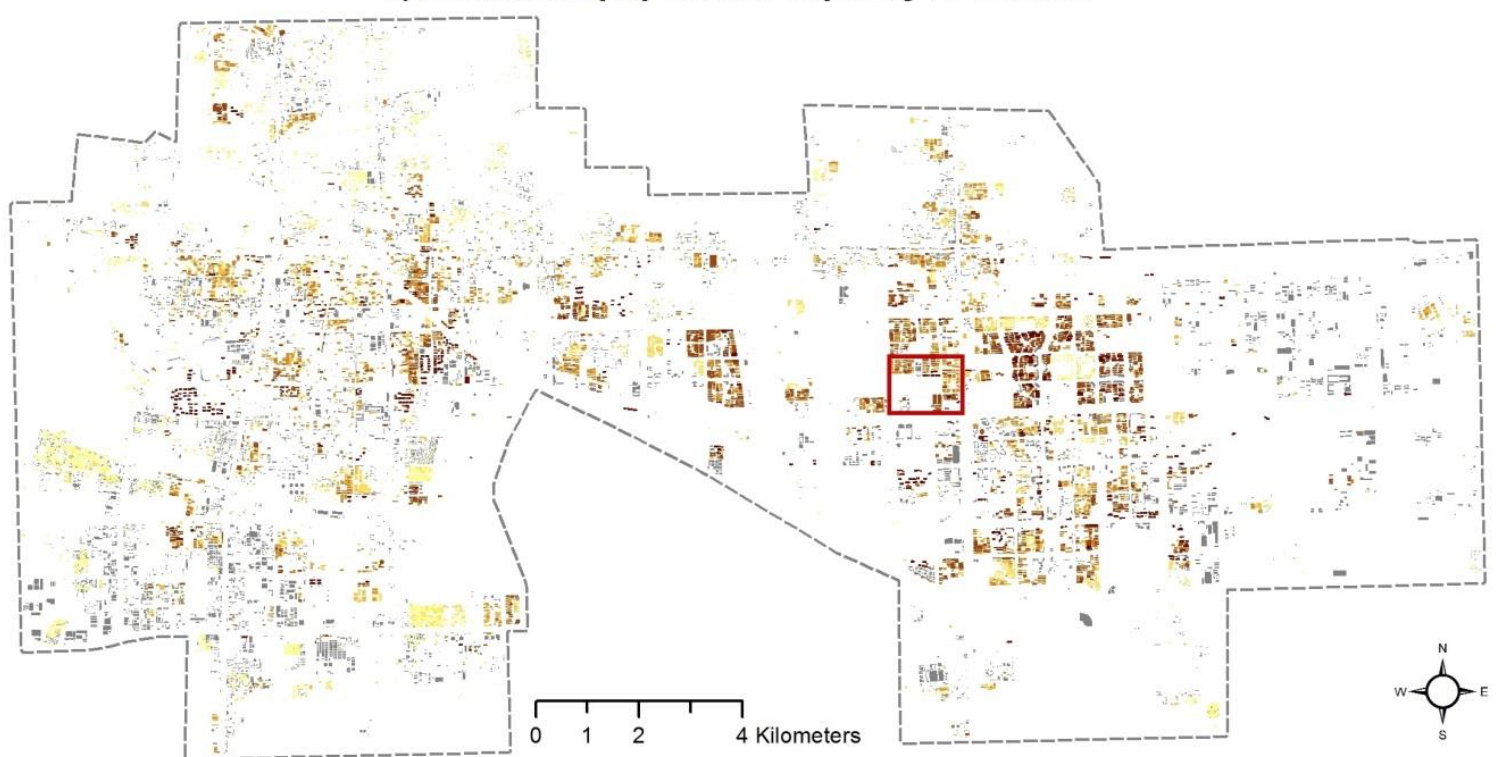

c) Details of multi-temporal population capacity estimates

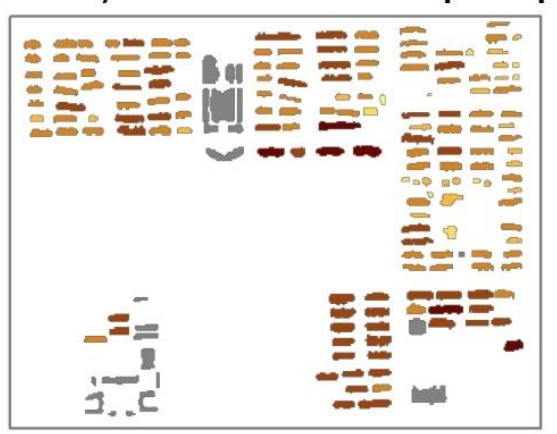

$2006 / 2007$

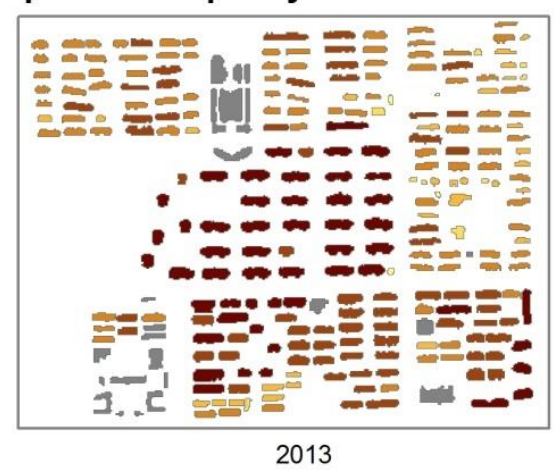

population per building

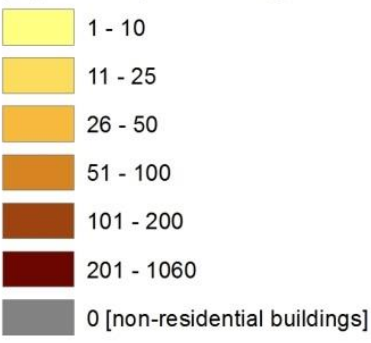

Fig. 7: Multi-temporal estimation of population capacity at building level for the city of Dongying. a) Population per building in $2013\left(\mathrm{t}_{1}\right)$. b) Estimated population capacity in 2006/2007 ( $\left.\mathrm{t}_{0}\right)$. c) Details of multitemporal population capacity estimation. 
As shown in Fig. 7, the general spatial pattern of the estimated population capacities reflects the combined results of change detection and building types classification, while large high-rise residential buildings provide living space for a large number of people as opposed to low buildings with small area. The smallest buildings in Dongying provide room for one person each, while the largest residential building is capable of hosting 1,060 people. In total, the summarized population capacity of Dongying is 587,914 people for $2006 / 2007$, while this number increases to $1,188,749$ for the year 2013 . The increase of the building inventory corresponds to an increase of population capacity of $102 \%$ within the considered time span of $6 / 7$ years.

\subsection{Assessment of the ghost city phenomenon}

For the assessment of the presence or absence of the ghost city phenomenon, the aggregated numbers of estimated population capacity in Dongying were related to census counts of the administrative unit of Dongying municipality. Although the study area possesses a large spatial overlap with Dongying municipality (Fig. 2a), census counts of all five municipalities (i.e., Dongying district) were consulted in addition for consideration of the wider context of the YRD. The multi-temporal comparison of estimated population capacity and census counts (Fig. 8) according to the statistical yearbooks for Dongying municipality (blue graph in Fig. 8) show very good agreement in 2006/2007 (estimated total population capacity of 587,914 opposed to 611,000 people in 2006 and 616,000 people in 2007 according to census), but large disagreement in 2013 (estimated total population capacity of $1,188,749$ opposed to 598,000 people according to census). Thus, the estimated population capacity in 2006/2007 deviates $4.17 \%$ from the census counts, while in 2013 the relative difference is 98.79\%. The development of census counts in Dongying district according to the statistical yearbooks (orange graph in Fig. 8) underlines the validity of the evolution of population counts in Dongying municipality. In conclusion, the estimated population capacity massively exceeds population counts in 2013 and thus, the assessment in this study reveals severe undercapacity with respect to permanent residential population within the urban area of Dongying. In other words, the emergence of the ghost city phenomenon can be considered highly likely within the time period of monitoring according to the definition of this study. 


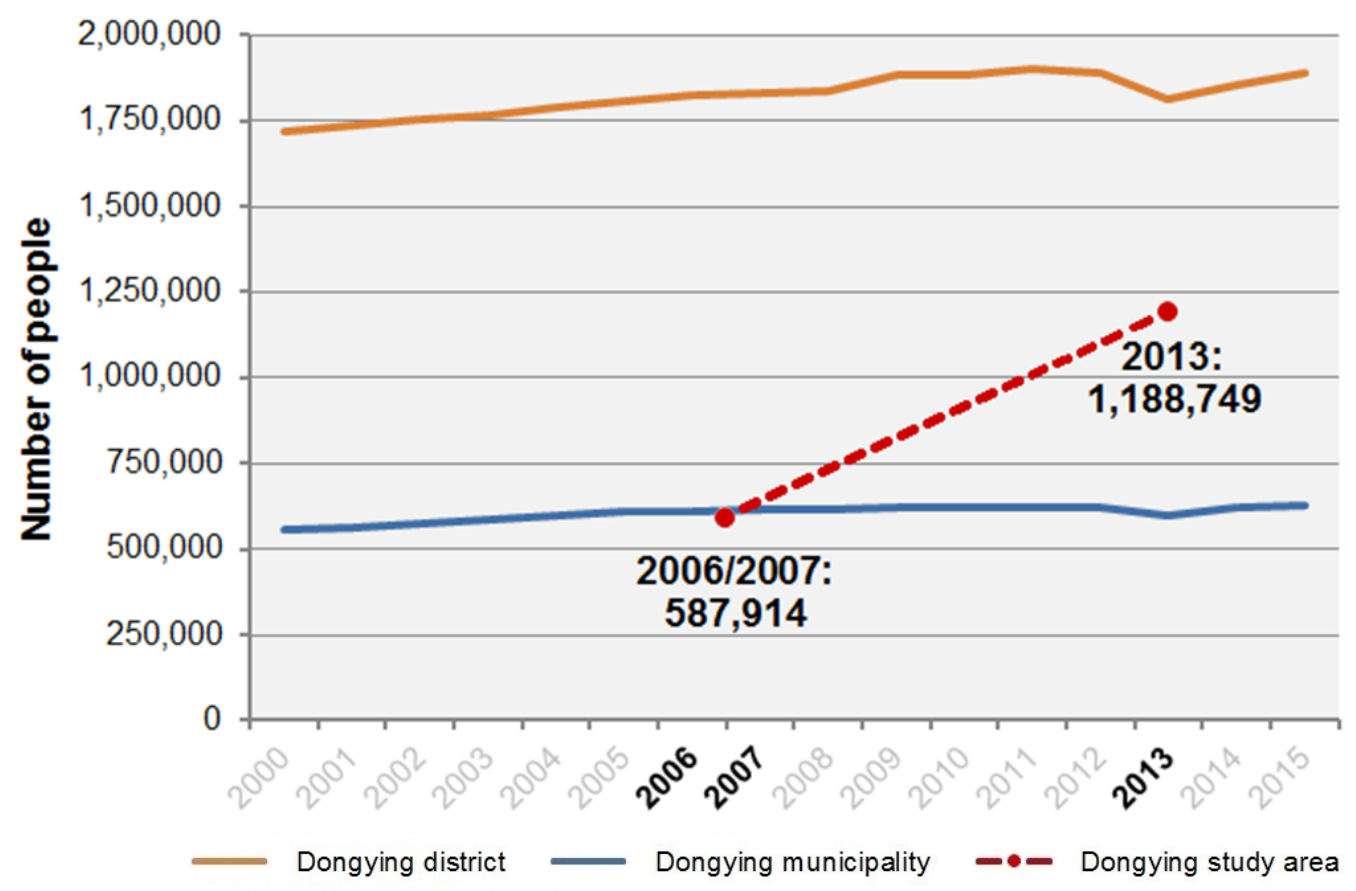

Fig. 8: Multi-temporal comparison of population capacity estimates in 2006/2007 $\left(\mathrm{t}_{0}\right)$ and 2013 ( $\mathrm{t}_{1}$ ) (red) with census counts of Dongying district (orange) and Dongying municipality (blue).

The calculated index describing the ghost city phenomenon and its spatial distribution is presented in Fig. 9. Besides index values of individual buildings, its mean value at the block level (defined according to the road network) is displayed for spatial aggregation and generalization and reveals specific regions of the urban area which are most likely to suffer from the ghost city phenomenon. Obviously, these areas correspond to the synopsis of the $4 \mathrm{~d}$ functional city model and multi-temporal population capacity estimates. Based on the citywide findings that in 2006/2007 the estimated population capacity matches census counts quite exactly, specific spatial conclusions are feasible. Since census counts are only available for the complete city extent, an equal trend is implicitly applied to all residential buildings in this study. However, assuming that the majority of the residents in Dongying do not migrate within the city during the 6/7 years of monitoring and the actual population of the city does not change, newly established quarters of large and high-rise residential buildings are most likely to suffer from the ghost city phenomenon (Fig. 9), which was also concluded by Shepard (2015), Jin, et al. (2017), and Ma, et al. (2018). Accordingly based on the more or less stable population of Dongying city, existing (i.e. unchanged) residential areas are less likely to suffer from the ghost city phenomenon as shown in Fig. 9. 
a) Spatial assessment of the ghost city phenomenon

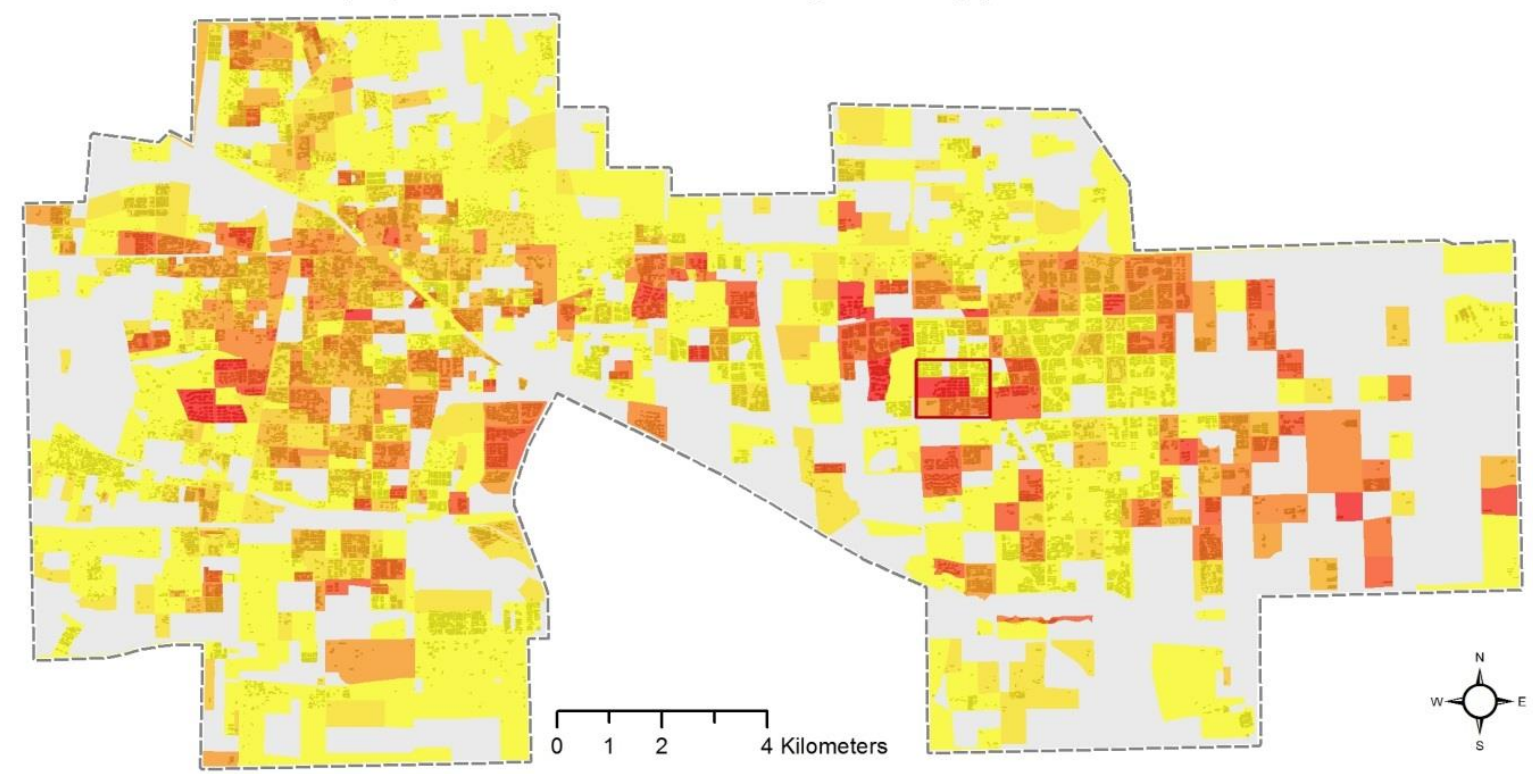

b) Detail of the spatial assessment of the ghost city phenomenon

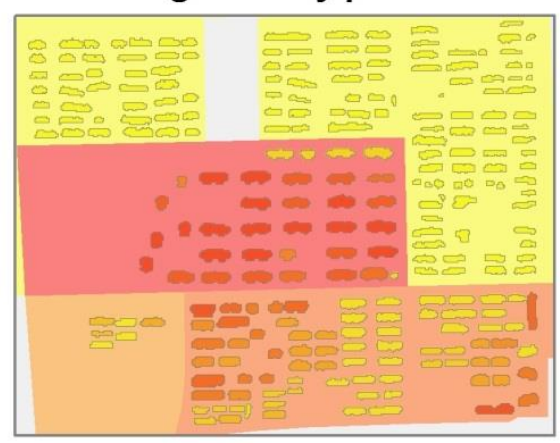

Likelihood of the presence of the ghost city phenomenon

high

low

Fig. 9: Spatial dynamics of the estimated population capacity related to census counts: a) Spatial assessment of the ghost city phenomenon, and b) Detail of the spatial assessment of the ghost city phenomenon.

\section{DISCUSSION}

This paper demonstrated a framework for the assessment of the ghost city phenomenon based on VHR remote sensing data as well as census counts and revealed significant evidence for the emergence and presence of the ghost city phenomenon in case of the Chinese city of Dongying.

Foremost, the proposed methodological framework is based on a $4 \mathrm{~d}$ functional city model. The methodology of unsupervised change detection for setup of the multi-temporal building model is discussed in detail in 
Leichtle, et al. (2017a), whereas the obtained accuracy for the study area of $\kappa=0.73, F=0.85$, and TSS $=$ 0.73 is similar to related work (e.g., Huang, et al. (2017), Lefebvre and Corpetti (2017)). With respect to the classification of building types, numerous studies have proven the utility of the RF classifier since its introduction by Breiman (2001). The accuracy of building types classification $(\kappa=0.89, F=0.93$, TSS $=$ 0.89) was comparable to existing studies in literature (e.g., Belgiu, et al. (2014), Geiß, et al. (2015), Wurm, et al. (2016)). The number of floors was determined based on linear transformation of building height with a high coefficient of determination of 0.91 . Thus, the $4 \mathrm{~d}$ functional city model provides a reliable data set of high thematic and geometric detail as well as high accuracies for characterization of the physical morphology and building functionality of the city. Subsequently, this information was employed for population capacity estimation based on a statistical approach for city-wide assessment of available living space and the potential number of inhabitants at building level. Other studies in literature found good accuracies using the statistical approach for population estimation, e.g., Wang, et al. (2016) achieve a mean relative error of $16.46 \%$ compared to census counts while Tomás, et al. (2016) underestimate the population by only $1.36 \%$. In comparison, the estimated population capacity in $2006 / 2007$ from this study deviates $4.17 \%$ from the respective census count for Dongying municipality, which indicates the validity of the relationship between the $4 \mathrm{~d}$ functional city model with estimated population capacity and census data. However, quantitative validation of the multi-temporal population capacity estimation is challenging since detailed area-wide, reliable ground truth information is not existent in this regard.

In addition, the methodological framework in this study encompasses known sources of error. First, the accuracy of change detection could be improved slightly by adjustment or correction of building parallax distortions, especially in case of high-rise buildings as presented in Leichtle, et al. (2017a). Furthermore, buildings under construction are classified as changed buildings and are included in the population estimation. However, as construction time is comparatively short in China, this leads to a short temporal inconsistency only. Second, mixed functions within individual buildings (e.g., commercial use on the ground-floor of residential buildings along shopping streets) might blur the precision with regard to classification of building types. In addition, the linkage of building types and associated functions might introduce uncertainties since it may not be unambiguous for all buildings. Third, the average floor height was calculated based on linear transformation of height for all residential buildings that includes certain variation (also see Fig. 6), which is not represented by the linear model. Fourth, errors and uncertainties with respect to the geometry of building footprints lead to loose representation of features for change detection as well as for classification of building types, but also cause under- or overestimation of available living space, especially in case of high-rise residential buildings. 
Nevertheless, the accuracy and the depth of detail in the $4 \mathrm{~d}$ functional city model surpass existing studies and provide a reliable description of the physical morphologic configuration and associated function within the city. Finally, the estimation of population capacity is dependent on several factors: Although the classification of building types is of good accuracy, there might be residential buildings of mixed functions as described above or additional non-residential space within residential units (e.g., storage space, utility rooms, garages, etc.) might exist that is not accounted to living space in reality. In this context, as mentioned above, the linear estimation of the average floor height influences the accuracy of the calculation of the number of floors. Furthermore, the living space per capita may vary considerably dependent on social and economic factors within the city area (Wu, et al., 2008), e.g., villa-type residential buildings possess significantly higher living space per capita compared to residential buildings of ordinary or poor living conditions. In addition, the utilized value of living space per capita is based on the year 2013 as a reference and could have changed (most likely increased) since 2006/2007 which might introduce a mismatch (most likely an overestimation) of population capacity. The utilized value of living space per capita is of high importance in general, since it significantly determines the absolute numbers of population estimation, as highlighted by Taubenböck and Wurm (2015). Nevertheless, this uncertainty is anticipated by the multi-temporal population estimation since the temporal characteristics of population capacity estimates are preserved regardless of the exact number of living space per capita.

A crucial point for the comparison of population capacity estimates against census counts are uncertainties related to census data from the statistical yearbooks employed in this study. The mismatch of administrative boundaries and the spatial extent of the remote sensing data analysis induces sources of error. Due to the large overlap of the study area with Dongying municipality (Fig. 2a), census counts of this administrative unit were considered in particular while the numbers of all five municipalities (i.e., Dongying district) were consulted additionally for incorporation of the wider context of the YRD. Besides the general uncertainties in the inference of census counts on the permanent residential population (Simpson, 2007), an important peculiarity of census counts in China is the hukou (household registration) system, which assigns a registration status of 'urban' or 'rural' to each citizen that is reflected in census numbers and can only be changed by the government (Ren, 2013). Thus, permanent migration from rural to urban areas in the formal sense (i.e., hukou migration) is highly regulated and mostly only possible for the very rich, the highly educated or direct family members of citizens with urban hukou (Chan \& Buckingham, 2008). In fact, most of the rural-urban migrants are rural migrant workers (i.e., people with rural hukou working in urban areas), who are not captured by official census counts and whose number increased to 221 million people in 2010 according to Chan (2012), whereas 7 million people account for Shandong province (total population of Shandong province according to census in 2010: 95,790,000) 
(Liang, et al., 2014). At the same time, the number of hukou migrants (i.e., permanent migrants) remained relatively stable at low numbers (Chan, 2012). This relatively high number of floating population in turn also affects census counts which represent de jure population (in contrast to de facto population) (Wu, et al., 2005). However, rural migrant workers have very limited access to the local real estate market due to their rural hukou status and mostly live in dormitories provided by their employers (Wong, et al., 2007).

For the decision on the presence or absence of the ghost city phenomenon, the dynamics of estimated population capacity are opposed to the dynamics of census counts. With respect to the comparison at the city level, the estimated population capacity matches census counts in 2006/2007 very well but a large disagreement was found in 2013 for the example of the city of Dongying. Nevertheless, both numbers are not free of errors which could imply either an underestimation of population by means of census or an overestimation of population capacity justifying the mismatch in 2013 . However, the temporal evolution of economic indicators in Dongying municipality and Dongying district (Shangdong Provincial Bureau of Statistics, 2001-2016) clearly underlines the strong economic as well as the rapid urban development. For example, according to the statistical yearbooks of Shandong province, the Gross Domestic Product (GDP) increased by 109\% in Dongying district (GDP in $20006 / 2007$ 155,756 Mio. $¥$, GDP in 2013325,020 Mio. $¥$ ) while the investment in fixed asset increased by $252 \%$ in Dongying municipality (12,089 Mio. ¥ in 2006/2007, 42,539 Mio. ¥ in 2013). These numbers support the strong construction activity identified by the $4 \mathrm{~d}$ functional city model since expansion of urban land is highly correlated to growth of GDP in China (Seto, et al., 2011). In addition to the quantitative accuracy assessment of the multi-temporal building model, this underlines the validity of the dynamics of population capacity estimation. In contrast, the accuracy of census counts remains unclear as mentioned above since reliable and detailed ground truth information is not existent in this regard. Regardless of these uncertainties, this study revealed a viable large multi-temporal disagreement of the change in available living space (i.e. population capacity) compared to the temporal development of census counts (Fig. 8) which confirms the presence of the ghost city phenomenon. The detailed spatial assessment (Fig. 9) provides an impression of specific regions of the urban area which are most likely to suffer from the ghost city phenomenon and revealed that large new residential developments are most likely affected. Since the dynamics of census counts are only available at the administrative municipality level which covers the complete study area, the particular spatial variability of the permanent residential population distribution at the building level cannot be captured due to the lack of more detailed data. However, the detailed spatial results appear feasible based on the conceptual definition of the ghost city phenomenon in this study and also coincide with the findings of Shepard (2015), Jin, et al. (2017), and Ma, et al. (2018). In addition, the methodology of the proposed index allows utilization of more 
detailed census counts for a more accurate spatial assessment if such data is available, however this might shift the arrangement of the detailed spatial assessment due to issues with respect to modified areal units (Openshaw, 1984).

In view of existing studies assessing the ghost city phenomenon, Standard Ranking (2015) did not identify Dongying being part of the top 50 ghost cities of China. In contrast, Chi, et al. (2015) include Dongying in their list of 20 Chinese ghost cities based on GPS data. Although Jin, et al. (2017) do not incorporate Dongying in their final ranking of the top 30 ghost cities of China, it is evident from their analyses that Dongying exhibits a relatively high ghost city index according to the authors definition. As described above, this study found feasible evidence for the emergence and presence of the ghost city phenomenon in the city of Dongying. Nevertheless, the future development of construction activities as well as census counts must be observed and analyzed according to the methodological framework presented in this study in order to provide continuous monitoring of the evolution of the ghost city phenomenon in Dongying.

\section{CONCLUSION}

This paper presents a framework for multi-temporal and spatially detailed assessment of the presence or absence of the ghost city phenomenon by means of multi-temporal VHR remote sensing data using the Chinese city of Dongying as an example. The conceptual framework of this study is based on the hypothesis that the available living space massively exceeds the actual population in case of presence of the ghost city phenomenon. In detail, the presence or absence of the ghost city phenomenon is assessed by multi-temporal confrontation of available living space of residential buildings (i.e. population capacity) and multi-temporal census counts. The multi-temporal population capacity estimation based on a $4 \mathrm{~d}$ functional city model incorporates a multi-temporal building model, building types in terms of function, as well as the number of floors of each building. In case of Dongying, the multi-temporal analysis revealed a considerable mismatch of estimated population capacity based on remote sensing and permanent residential population numbers from census counts. In other words, the physical manifestation of urbanization does not match the population development and thus, this study found reasonable evidence for the presence of the ghost city phenomenon in Dongying. 
In general, the ghost city phenomenon mostly affects rapid developing small and medium sized cities in China (Jin, et al., 2017). In China, a crucial factor with respect to this phenomenon is the strong influence of planning on urban development, which is largely controlled by the government. From a more general perspective, Shepard (2015) argues that in fact, the ghost city phenomenon represents a transition period of construction and occupancy of newly constructed buildings, which is a common process in newly developed districts in Chinese cities. The open question of all new developments is whether and when these new urban centers will be populated, which still remains unanswered for the city of Dongying.

Thus, continuous monitoring is indispensable for present ghost cities like Dongying in order to reach a final decision on the persistent presence of the ghost city phenomenon and their future development. From a data perspective, additional information especially on human activities might be included as additional indicators for comprehensive understanding of the characteristics and evolution of potential ghost cities. Consequently, the employed methodology must be constantly improved and emerging techniques for supervised as well as unsupervised image classification and change detection as well as associated object-based features must be evaluated and included. For broader understanding of the ghost city phenomenon and related processes, future investigations must also incorporate additional Chinese cities and larger spatial scales.

\section{ACKNOWLEDGEMENT}

This research was conducted in the context of the DELIGHT project (www.delight.eoc.dlr.de, grant no. 02WCL1249A and 02WCL1249I) funded by the German Federal Ministry of Education and Research, BMBF. Additional funds were received from the European Research Council (ERC) under the European Union's Horizon 2020 research and innovation program (grant no. 714087 - So2Sat). The authors would like to thank Matthias Boes (European Space Imaging, EUSI) for providing the WorldView imagery and Dr. Klaus Martin (Company for Remote Sensing and Environmental Research, SLU) for his support. The authors would also like to thank the anonymous reviewers for their very helpful comments and suggestions. 


\section{REFERENCES}

Allouche, O., Tsoar, A., \& Kadmon, R. (2006). Assessing the accuracy of species distribution models: prevalence, kappa and the true skill statistic (TSS). Journal of Applied Ecology, 43 (6), 1223-1232.

Belgiu, M., \& Drăguţ, L. (2016). Random forest in remote sensing: A review of applications and future directions. ISPRS Journal of Photogrammetry and Remote Sensing, 114, 24-31.

Belgiu, M., Tomljenovic, I., Lampoltshammer, T., Blaschke, T., \& Höfle, B. (2014). Ontology-Based Classification of Building Types Detected from Airborne Laser Scanning Data. Remote Sensing, 6 (2), 1347.

Biljecki, F., Arroyo Ohori, K., Ledoux, H., Peters, R., \& Stoter, J. (2016). Population Estimation Using a 3D City Model: A Multi-Scale Country-Wide Study in the Netherlands. PLOS ONE, 11 (6), e0156808.

Breiman, L. (2001). Random Forests. Machine Learning, 45 (1), 5-32.

Chan, K. W. (2012). Migration and development in China: trends, geography and current issues. Migration and Development, 1 (2), 187-205.

Chan, K. W., \& Buckingham, W. (2008). Is China Abolishing the Hukou System? The China Quarterly, 195, 582-606

Chi, G., Liu, Y., \& Wu, H. (2015). Ghost Cities Analysis Based on Positioning Data in China, arXiv preprint arXiv:1510.08505.

Comitee of the Dongying urban and rural planning bureau. (2011). Dongying urban and rural planning. China Publishing House.

Fang Ranking. (2015). Top 12 "ghost cities" of China in 2015. In, http://news.anshan.fang.com/2015-1208/18506456_all.htm

Foody, G. M. (2002). Status of land cover classification accuracy assessment. Remote Sensing of Environment, 80 (1), 185-201.

Geiß, C., Aravena Pelizari, P., Marconcini, M., Sengara, W., Edwards, M., Lakes, T., \& Taubenböck, H. (2015). Estimation of seismic building structural types using multi-sensor remote sensing and machine learning techniques. ISPRS Journal of Photogrammetry and Remote Sensing, 104, 175-188.

He, G., Mol, A. P. J., \& Lu, Y. (2016). Wasted cities in urbanizing China. Environmental Development, 18, 2-13.

Huang, X., Wen, D., Li, J., \& Qin, R. (2017). Multi-level monitoring of subtle urban changes for the megacities of China using high-resolution multi-view satellite imagery. Remote Sensing of Environment, 196, 56-75. 
Jin, X., Long, Y., Sun, W., Lu, Y., Yang, X., \& Tang, J. (2017). Evaluating cities' vitality and identifying ghost cities in China with emerging geographical data. Cities, 63, 98-109.

Kuenzer, C., Ottinger, M., Liu, G., Sun, B., Baumhauer, R., \& Dech, S. (2014). Earth observation-based coastal zone monitoring of the Yellow River Delta: Dynamics in China's second largest oil producing region over four decades. Applied Geography, 55, 92-107.

Lefebvre, A., \& Corpetti, T. (2017). Monitoring the Morphological Transformation of Beijing Old City Using Remote Sensing Texture Analysis. IEEE Journal of Selected Topics in Applied Earth Observations and Remote Sensing, 10 (2), 539-548.

Leichtle, T., Geiß, C., Wurm, M., Lakes, T., \& Taubenböck, H. (2017a). Unsupervised change detection in VHR remote sensing imagery - an object-based clustering approach in a dynamic urban environment. International Journal of Applied Earth Observation and Geoinformation, 54, 15-27.

Leichtle, T., Geiß, C., Wurm, M., Lakes, T., \& Taubenböck, H. (2017b). Evaluation of clustering algorithms for unsupervised change detection in VHR remote sensing imagery. In 2017 Joint Urban Remote Sensing Event (JURSE) (pp. 1-4).

Li, X., \& Gong, P. (2016). An “exclusion-inclusion” framework for extracting human settlements in rapidly developing regions of China from Landsat images. Remote Sensing of Environment, 186, 286-296.

Liang, Z. (2001). The Age of Migration in China. Population and Development Review, 27 (3), 499-524.

Liang, Z., Li, Z., \& Ma, Z. (2014). Changing Patterns of the Floating Population in China during 2000-2010. Population and Development Review, 40 (4), 695-716.

Liaw, A., \& Wiener, M. (2002). Classification and regression by randomForest. $R$ news, 2 (3), 18-22.

Lu, Z., Im, J., Rhee, J., \& Hodgson, M. (2014). Building type classification using spatial and landscape attributes derived from LiDAR remote sensing data. Landscape and Urban Planning, 130, 134-148.

Ma, T., Zhou, Y., Zhou, C., Haynie, S., Pei, T., \& Xu, T. (2015). Night-time light derived estimation of spatiotemporal characteristics of urbanization dynamics using DMSP/OLS satellite data. Remote Sensing of Environment, 158, 453-464.

Ma, X., Tong, X., Liu, S., Li, C., \& Ma, Z. (2018). A Multisource Remotely Sensed Data Oriented Method for “Ghost City" Phenomenon Identification. IEEE Journal of Selected Topics in Applied Earth Observations and Remote Sensing, 11 (7), 2310-2319.

NetEase Ranking. (2015). The urban construction speed exceeds population growth in many cities of China, a large number of "ghost cities" appeared. In, http://news.163.com/15/1209/01/BABTGM1000014MTN.html. 
O'Callaghan, C., Boyle, M., \& Kitchin, R. (2014). Post-politics, crisis, and Ireland's 'ghost estates'. Political Geography, 42, 121-133.

Openshaw, S. (1984). The modifiable areal unit problem (Vol. 38). Geo Books, Norwich, United Kingdom.

Ottinger, M., Kuenzer, C., Liu, G., Wang, S., \& Dech, S. (2013). Monitoring land cover dynamics in the Yellow River Delta from 1995 to 2010 based on Landsat 5 TM. Applied Geography, 44, 53-68.

Ren, X. (2013). Urban China. Polity Press, Malden, USA.

Richter, R. (1996). A spatially adaptive fast atmospheric correction algorithm. International Journal of Remote Sensing, 17 (6), 1201-1214.

Ruibo, H., \& Linna, W. (2013). Challenges and opportunities facing China's urban development in the new era: A statistical and spatial analysis. China Perspectives, 2013 (2), 15-28.

Schneider, A., Friedl, M. A., \& Potere, D. (2010). Mapping global urban areas using MODIS 500-m data: New methods and datasets based on 'urban ecoregions'. Remote Sensing of Environment, 114 (8), 1733-1746.

Schneider, A., \& Mertes, C. M. (2014). Expansion and growth in Chinese cities, 1978-2010. Environmental Research Letters, 9 (2), 024008.

Seto, K. C., Fragkias, M., Güneralp, B., \& Reilly, M. K. (2011). A Meta-Analysis of Global Urban Land Expansion. PLOS ONE, 6 (8), e23777.

Shangdong Provincial Bureau of Statistics. (2001-2016). Shandong Statistical Yearbook. China Statistics Press, Beijing, China.

Shepard, W. (2015). Ghost Cities of China. Zed Books, London, United Kingdom.

Shi, L., Taubenböck, H., Zhang, Z., Liu, F., \& Wurm, M. (2017). Urbanization in China from the end of 1980s until 2010 - spatial dynamics and patterns of growth using EO-data. International Journal of Digital Earth, 1-17.

Simpson, L. (2007). Fixing the Population: From Census to Population Estimate. Environment and Planning A: Economy and Space, 39 (5), 1045-1057.

Standard Ranking. (2015). "Ghost city" ranking in China. In, http://www.biaozhun007.com/articles/5b3ea9ac91f2fa89.html.

Taubenböck, H., Esch, T., Felbier, A., Wiesner, M., Roth, A., \& Dech, S. (2012). Monitoring urbanization in mega cities from space. Remote Sensing of Environment, 117, 162-176.

Taubenböck, H., Wiesner, M., Felbier, A., Marconcini, M., Esch, T., \& Dech, S. (2014). New dimensions of urban landscapes: The spatio-temporal evolution from a polynuclei area to a mega-region based on remote sensing data. Applied Geography, 47, 137-153. 
Taubenböck, H., \& Wurm, M. (2015). Ich weiß, dass ich nichts weiß - Bevölkerungsschätzung in der Megacity Mumbai. In H. Taubenböck, M. Wurm, T. Esch \& S. Dech (Eds.), Globale Urbanisierung: Perspektive aus dem All (pp. 171-178). Springer Berlin Heidelberg, Berlin, Heidelberg.

Thompson, E. S., \& de Beurs, K. M. (2018). Tracking the removal of buildings in rust belt cities with opensource geospatial data. International Journal of Applied Earth Observation and Geoinformation, 73, 471481.

Tomás, L., Fonseca, L., Almeida, C., Leonardi, F., \& Pereira, M. (2016). Urban population estimation based on residential buildings volume using IKONOS-2 images and lidar data. International Journal of Remote Sensing, 37 (sup1), 1-28.

United Nations, Department of Economic and Social Affairs, Population Division. (2014). World Urbanization Prospects: The 2014 Revision, Highlights (ST/ESA/SER.A/352). In.

Van Rijsbergen, C. J. (1979). Information Retrieval. Butterworths.

Wang, S., Tian, Y., Zhou, Y., Liu, W., \& Lin, C. (2016). Fine-Scale Population Estimation by 3D Reconstruction of Urban Residential Buildings. Sensors, 16 (10), 1755.

Wong, D. F. K., Li, C. Y., \& Song, H. X. (2007). Rural migrant workers in urban China: living a marginalised life. International Journal of Social Welfare, 16 (1), 32-40.

World Bank, \& Development Research Center of the State Council, the People's Republic of China. (2014). Urban China: Toward Efficient, Inclusive, and Sustainable Urbanization. In, Washington, DC.

Wu, S.-S., Qiu, X., \& Wang, L. (2005). Population Estimation Methods in GIS and Remote Sensing: A Review. GIScience \& Remote Sensing, 42 (1), 80-96.

Wu, S.-S., Wang, L., \& Qiu, X. (2008). Incorporating GIS Building Data and Census Housing Statistics for SubBlock-Level Population Estimation. The Professional Geographer, 60 (1), 121-135.

Wurm, M., Schmitt, A., \& Taubenböck, H. (2016). Building Types Classification Using Shape-Based Features and Linear Discriminant Functions. IEEE Journal of Selected Topics in Applied Earth Observations and Remote Sensing, 9 (5), 1901-1912.

Wurm, M., Taubenböck, H., Schardt, M., Esch, T., \& Dech, S. (2011). Object-based image information fusion using multisensor earth observation data over urban areas. International Journal of Image and Data Fusion, $2(2), 121-147$.

Xie, Y., Gong, H., Lan, H., \& Zeng, S. (2018). Examining shrinking city of Detroit in the context of socio-spatial inequalities. Landscape and Urban Planning, 177, 350-361.

Xie, Y., Weng, A., \& Weng, Q. (2015). Population Estimation of Urban Residential Communities Using Remotely Sensed Morphologic Data. IEEE Geoscience and Remote Sensing Letters, 12 (5), 1111-1115. 
Xie, Y., \& Weng, Q. (2016). Updating urban extents with nighttime light imagery by using an object-based thresholding method. Remote Sensing of Environment, 187, 1-13.

Xu, X., Peng, H., Xu, Q., Xiao, H., \& Benoit, G. (2009). Land Changes and Conflicts Coordination in Coastal Urbanization: A Case Study of the Shandong Peninsula in China. Coastal Management, 37 (1), 54-69.

Zhang, K. H., \& Song, S. (2003). Rural-urban migration and urbanization in China: Evidence from time-series and cross-section analyses. China Economic Review, 14 (4), 386-400.

Zhang, Q., \& Seto, K. C. (2011). Mapping urbanization dynamics at regional and global scales using multitemporal DMSP/OLS nighttime light data. Remote Sensing of Environment, 115 (9), 2320-2329.

Zheng, H., Wang, X., \& Cao, S. (2014). The land finance model jeopardizes China's sustainable development. Habitat International, 44, 130-136.

Zheng, Q., Deng, J., Jiang, R., Wang, K., Xue, X., Lin, Y., Huang, Z., Shen, Z., Li, J., \& Shahtahmassebi, A. R. (2017a). Monitoring and assessing "ghost cities" in Northeast China from the view of nighttime light remote sensing data. Habitat International, 70, 34-42.

Zheng, Q., Zeng, Y., Deng, J., Wang, K., Jiang, R., \& Ye, Z. (2017b). “Ghost cities” identification using multisource remote sensing datasets: A case study in Yangtze River Delta. Applied Geography, 80, 112-121. 